\title{
Shaped Charge Hydraulic Blasting: An Environmental, Safe, and Economical Method of Directional Roof Cutting
}

\author{
Quan Zhang $\mathbb{D}^{1},{ }^{1}$ Jiong Wang $\mathbb{D}^{2},{ }^{2}$ Shan Guo, ${ }^{2}$ Weili Gong, ${ }^{2}$ Longfei Feng, ${ }^{3}$ Haosen Wang, \\ Can Ming, ${ }^{2}$ and Zimin $\mathrm{Ma}^{4}$ \\ ${ }^{1}$ School of Mines, China University of Mining and Technology, Xuzhou, Jiangsu 221116, China \\ ${ }^{2}$ State Key Laboratory of Geomechanics \& Deep Underground Engineering, China University of Mining and Technology, \\ Beijing 100083, China \\ ${ }^{3}$ Center of Mine Disaster Control and Environment Management Technology, Xi'an Research Institute of China Coal Technology \& \\ Engineering Group Corp, Xi'an, Shanxi 710054, China \\ ${ }^{4}$ School of Resources and Environmental Engineering, Shandong University of Technology, Zibo, Shandong 255049, China
}

Correspondence should be addressed to Quan Zhang; zhangquan@cumt.edu.cn and Jiong Wang; wangjiong0216@163.com

Received 17 January 2021; Revised 14 February 2021; Accepted 28 February 2021; Published 13 March 2021

Academic Editor: Feng Xiong

Copyright ( 2021 Quan Zhang et al. This is an open access article distributed under the Creative Commons Attribution License, which permits unrestricted use, distribution, and reproduction in any medium, provided the original work is properly cited.

\begin{abstract}
Shaped charge blasting (SCB) - a directional fracture blasting technology—has the disadvantages of low safety, harmful gas, and dust emissions. This study proposes a new type of directional rock-breaking technology called shaped charge hydraulic blasting $(\mathrm{SCHB})$ that uses water as the blasting medium instead of air. To verify the effectiveness of the new method, we performed a theoretical analysis. Twelve groups of on-site directional roof-cutting tests were carried out on SCB and SCHB for comparison in a coal mine. The results showed that, although both blasting methods achieved the goal of directional roof cutting for noncoal pillar mining, SCHB had greater blasting power and produced $8 \%$ higher crack rate than SCB for the same charge amount. SCHB required $12.5 \%$ less charge than SCB when the crack rate was basically the same. SCHB effectively reduced the concentration of CO. The maximum concentration of CO was reduced by $22-62 \%$ compared with SCB. The maximum concentration decreased parabolically with the monitoring distance. In addition, water can absorb high temperature and inhibit sparks from blasting, so SCHB can prevent gas explosions. Therefore, SCHB is an environmental, safe, and economical method of directional roof cutting, which has wide applications in mining and geotechnical engineering.
\end{abstract}

\section{Introduction}

Noncoal pillar mining does not need to manually or mechanically dig into the roadway. It automatically forms a roadway when coal is mined from the previous working face by roof cutting. It is known as the "the third mining science innovation" in China [1]. Directional roof cutting is one of the core technologies of this novel coal mining method. The principle of this method is shown in Figure 1.

Directional rock-breaking methods include soundless chemical demolition agents, water jets, directional hydraulic fracturing, slot hydraulic blasting, and shaped charge blasting (SCB). Soundless chemical demolition agents have been tested in the laboratory, and they can break the rock direc- tionally $[2,3]$. However, the demolition agents have the disadvantages of long reaction time [4], low power, and being easily affected by external temperature [5]. Therefore, it is not applied in directional roof cutting. The water jet can be precisely oriented to cut the roof, but it is difficult and timeconsuming to fix the nozzle with this method. Directional hydraulic fracturing involves creating a groove in the borehole and then performing hydraulic fracturing [6-8]. To a certain extent, it can be oriented to precrack the roof, but the technology has a limited range of crack orientation extension. After the crack has spread along the prefabricated slot for a distance, the direction of crack propagation is controlled by the magnitude and direction of the in situ stresses. Slot hydraulic blasting uses a water jet to cut a slot of a certain 


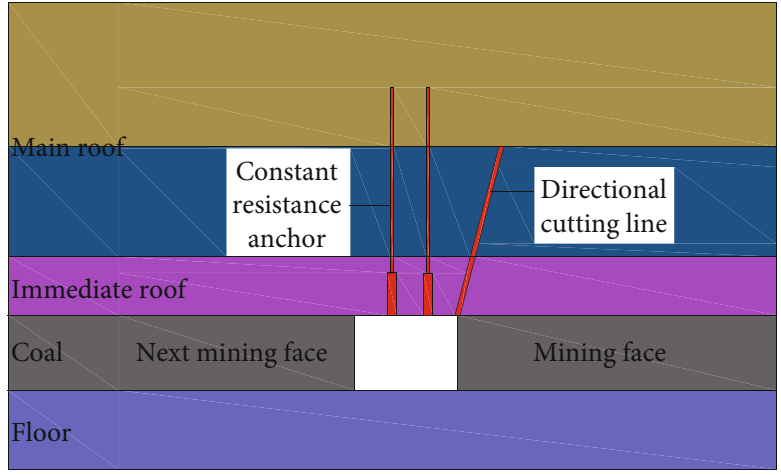

(a)

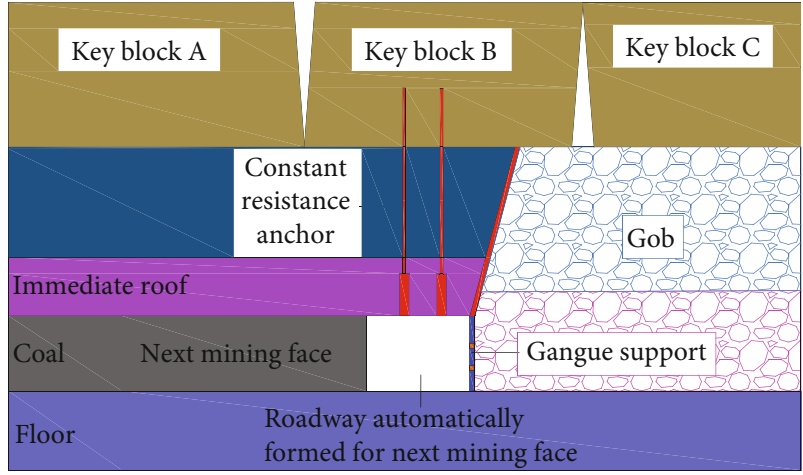

(b)

FIGURE 1: Schematic diagram of noncoal pillar mining with automatically formed roadway: (a) directional roof cutting and (b) roof collapses along the directional cutting line to form a roadway serving the next face.

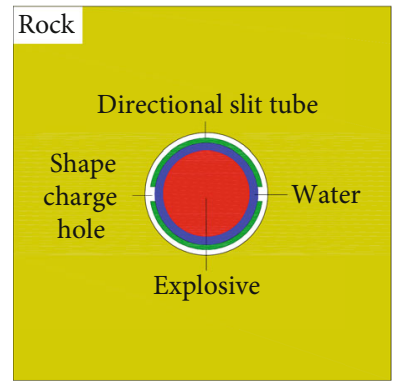

Shape charge hole

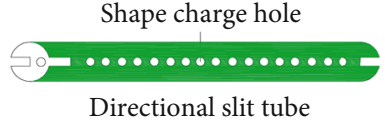

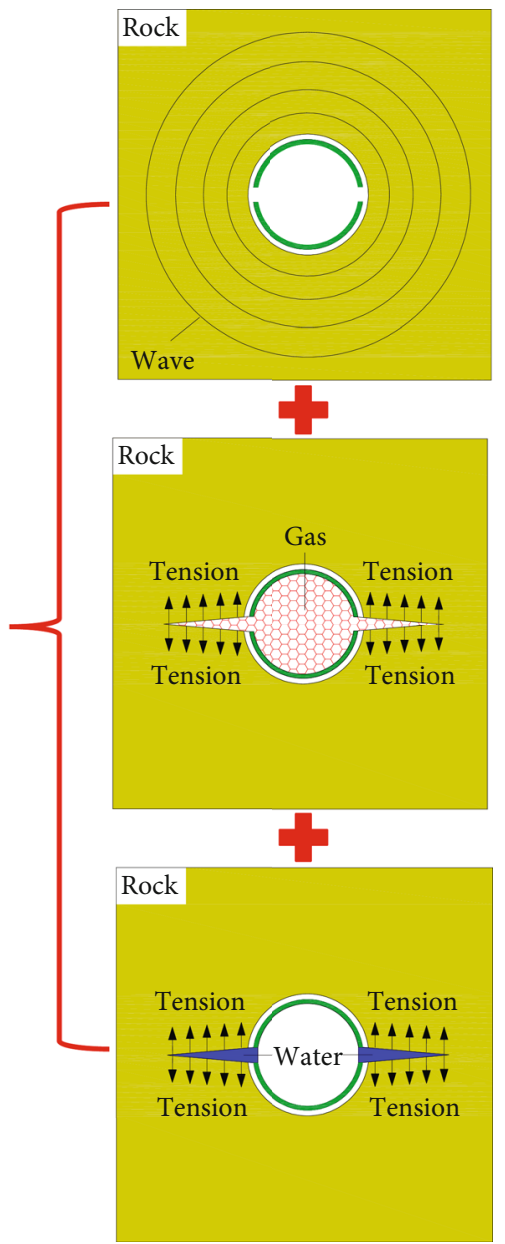

FIGURE 2: Charge structure and directional roof-cutting mechanism of shaped charge hydraulic blasting (SCHB).

width and length in the rock and then performs ordinary blasting [9]. The stress change in the direction of the slot tip is greater than in other directions, which causes the crack to initiate and expand along this direction [10]. However, the scope of directional expansion is limited, and it takes time and effort to cut slots. Therefore, these methods cannot be used for directional roof cutting. At present, the directional roof-cutting technology applied to noncoal pillar mining with roadway formed automatically is mainly SCB [11-13]. However, this method emits toxic and harmful gases [14, 15], large dust $[16,17]$, and other explosive substances. The explosion itself produces CO [18-20]. CO, which has 250300 times the hemoglobin binding capacity of $\mathrm{O}_{2}$, is not filtered by the lungs and causes hypoxia in various tissues and 


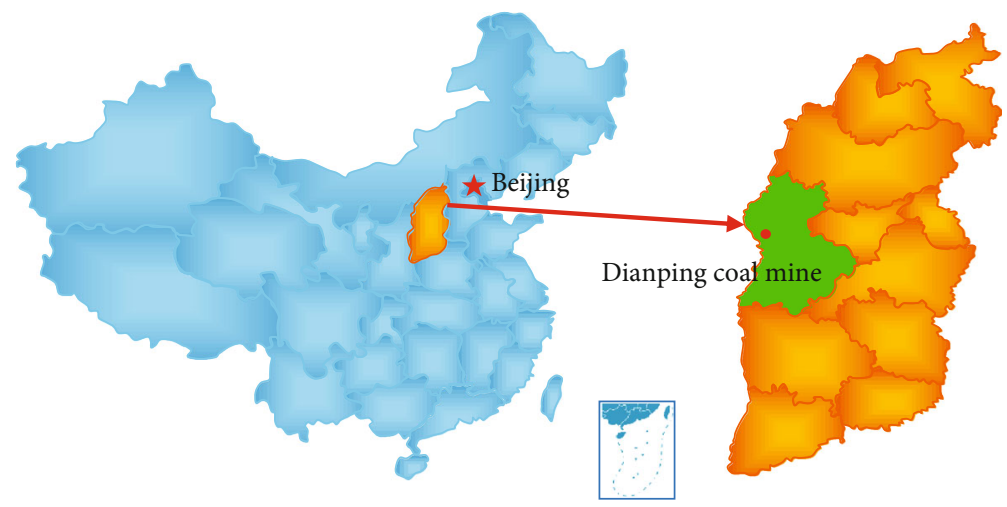

(a)

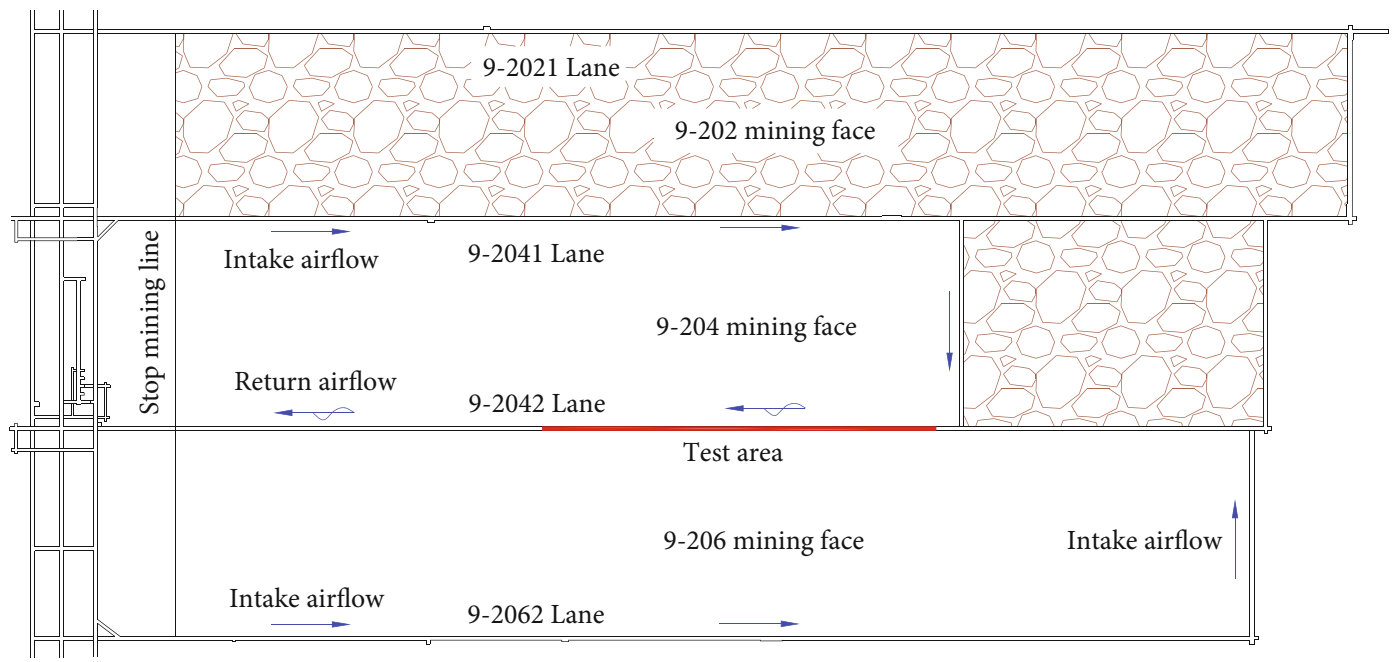

(b)

FIgure 3: Test site (Dianping Coal Mine): (a) location in China and (b) 9-2042 lane.

cells of the human body. If the concentration of $\mathrm{CO}$ exceeds $24 \mathrm{ppm}$, it will present different degrees of harm in different people. When its concentration is too high, CO may cause asphyxiation or even death. To reduce the emission of harmful gases and dust, engineers developed the hydraulic blasting technology. Hydraulic blasting replaces the air medium around the explosive in the traditional blasting with water medium, using water to transfer the blasting energy [21-23]. Water can absorb harmful gases and dust [24, 25], but conventional hydraulic blasting produces multiple cracks in the rock mass [26-29], and the propagation direction and number of cracks cannot be controlled. Rock fracture [30-35] is one of the core problems of geotechnical engineering [36-41], but there are not many methods of directional rock fracture.

A new directional rock-breaking method called shaped charge hydraulic blasting (SCHB), which combines the advantages of SCB and hydraulic blasting, was proposed. The technology can generate cracks in a directional way, reduce the amount of toxic gas, and save the explosive charge. It is a green, safe, and economical method of directional rock breaking. The mechanism of SCHB directional roof cutting is analyzed. SCB and SCHB roof cutting were tested in a coal mine. The directional roof-cutting effect, crack rate, explosive dosage, and $\mathrm{CO}$ concentration of the two methods were compared.

\section{Directional Roof-Cutting Mechanism of SCHB}

The charge structure and directional roof-cutting mechanism of SCHB are shown in Figure 2. The detonation of the explosive material in water produces a high-speed water jet in the blast hole, which in turn impinges a directional impact in the direction of the shaped charge holes. This process is like the high-pressure water-jet rock breaking. Due to the incompressibility, higher density, and larger flow viscosity of water, the effect of the explosive shock waves in water is more intense and prolonged than in air. The explosion stress wave generated in the water decays more gradually and has a higher peak explosion pressure. Therefore, this method can save explosives. The directional slit tube changes the propagating direction of explosive blasting energy, which makes the wave, water jet, and explosive gas propagate focus on the direction of shaped charge holes. The directional slit tube produces concentrated tension in two directions, while producing uniform pressure in the rest. When the stress at the hole wall exceeds the dynamic tensile strength of the rock, the roof is split directionally along the holes. Compared with the SCB explosive, the SCHB directional slit tube and the hole wall use water as the coupling medium. Because of its high specific 
TABLE 1: Mechanical parameters of roof rock.

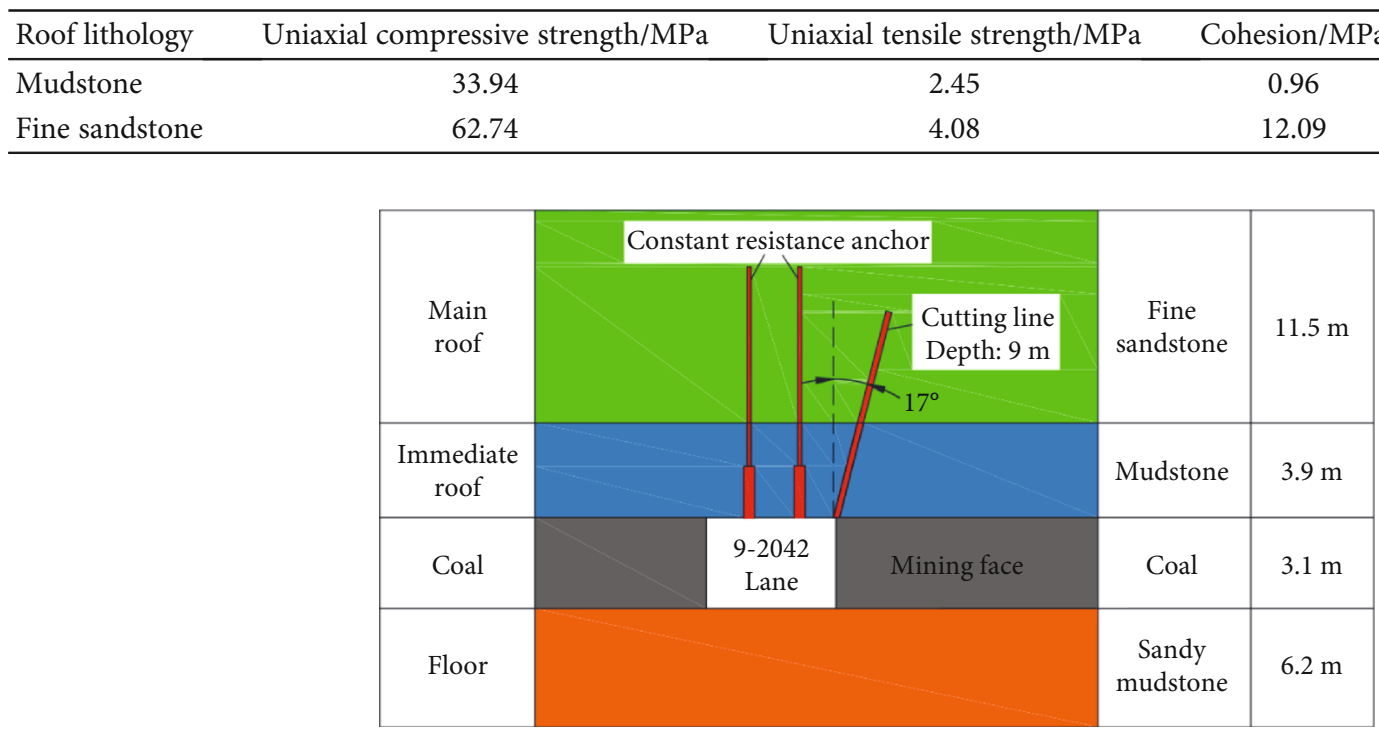

FigURE 4: Roof and floor lithology and roof-cutting parameters of 9-2042 roadway.

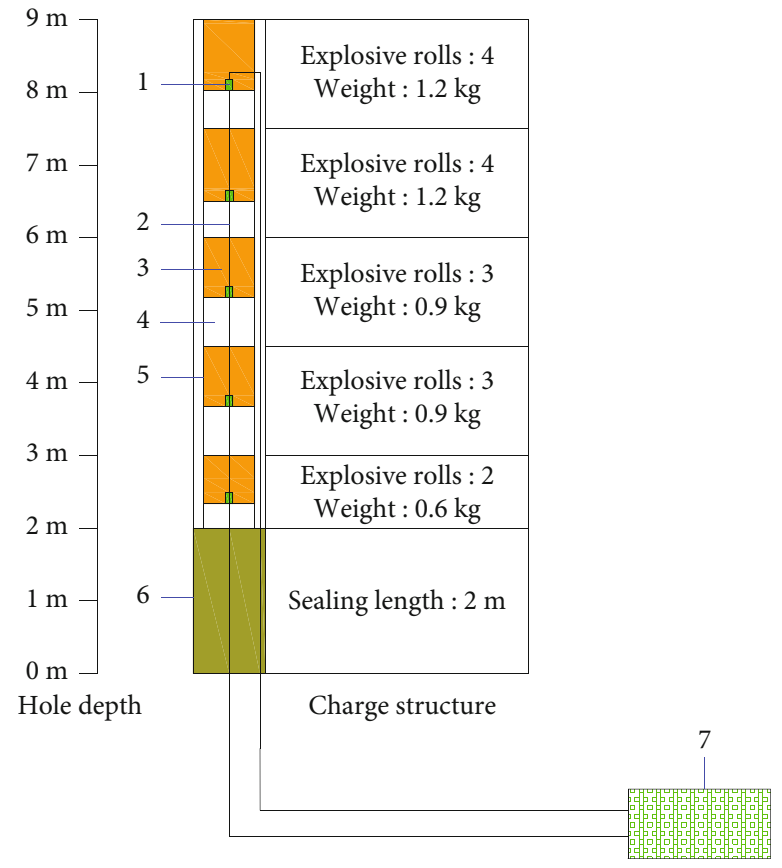

(a)

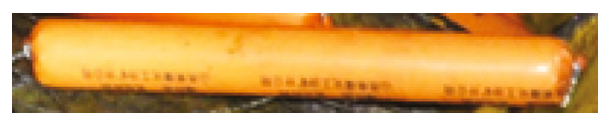

(b)

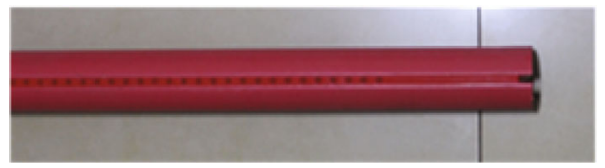

(c)

FIGURE 5: Charge structure of shaped charge blasting (SCB): (a) connection and charge structure in a single hole, (b) an explosive roll, and (c) directional slit tube (1: detonator; 2: connecting wire; 3: explosive; 4: air; 5: directional slit tube; 6: sealing mud; 7: detonating equipment). 


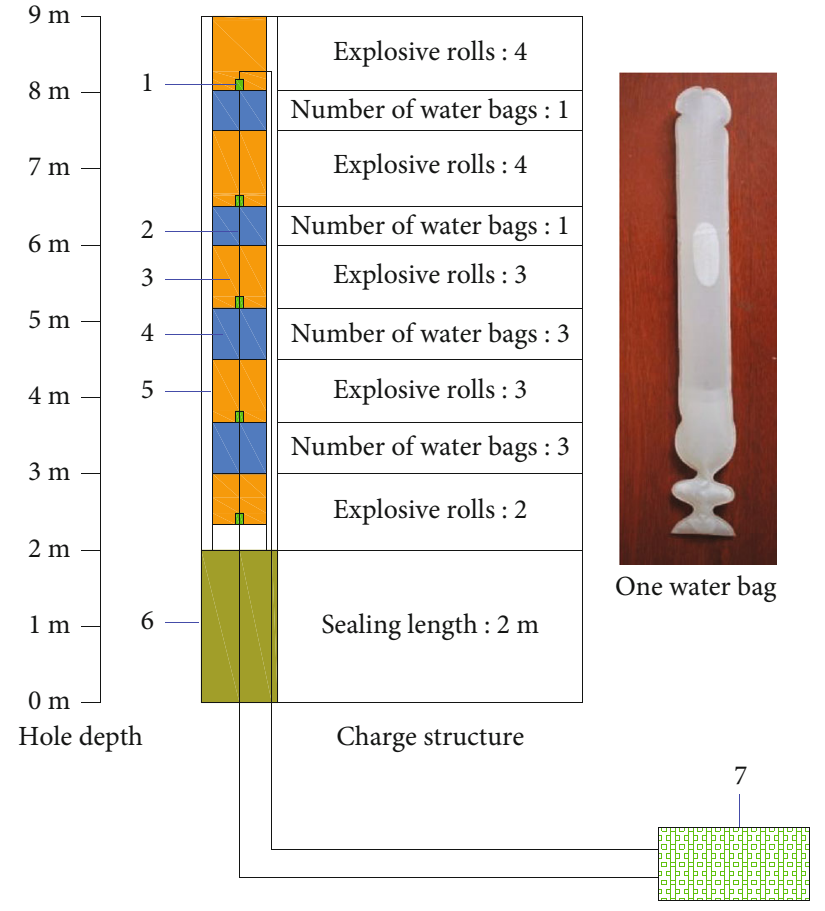

(a)

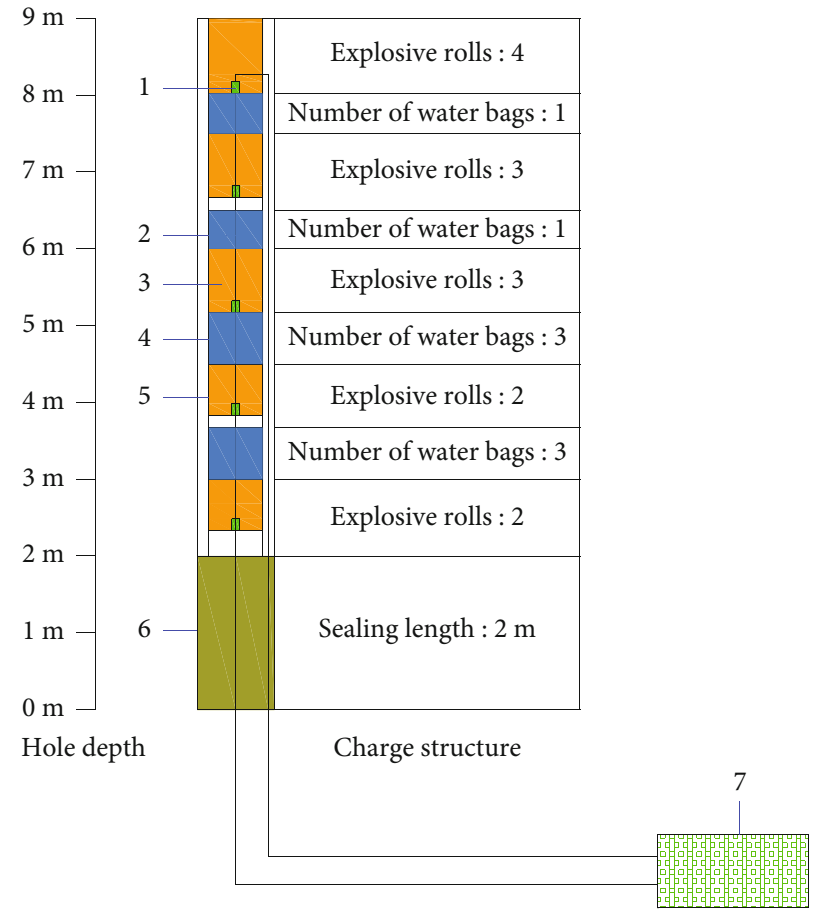

(b)

FIGURE 6: Charge structure of SCHB: (a) charge volume: $4.8 \mathrm{~kg}$ and (b) charge volume: $4.2 \mathrm{~kg}$ (1: detonator; 2: connecting wire; 3: explosive; 4 : water; 5: directional slit tube; 6: sealing mud; 7: detonating equipment).

heat capacity, water is good at absorbing the heat of the explosive gas, has obvious flame-extinguishing effect, and can reduce the risk of gas explosion. In addition, water can effectively absorb toxic gases and blasting dust and thus improve the working environment.

In summary, SCHB rock breaking has three effects: a dynamic pressure effect and two static pressure effects. Dynamic pressure occurs before static pressure and is basically the shock waves in water [42]. One type of static pressure is the gas wedge effect of the explosive gas in the direction of the energy-accruing holes, and the other type of static pressure is the water wedge effect of the high-speed water jet. The effect of static pressure extends the cracks that have already started.

The pressure $\left(P_{S}\right)$ of the shock wave in the water from the blasting point $R$ is

$$
\begin{gathered}
P_{S}=720 \bar{R}^{-0.72}, \\
\bar{R}=\frac{R}{\sqrt{Q_{c}}}, \\
Q_{c}=\frac{\pi d_{c}^{2} \rho_{0}}{4},
\end{gathered}
$$

where $\bar{R}$ is the proportional distance, $Q_{c}$ is the relative 2,4,6-trinitrotoluene equivalent of the explosive, $d_{c}$ is the diameter of the explosive roll, and $\rho_{0}$ is the density of the explosive [43].
Combining Eqs. (1), (2), and (3), we get

$$
P_{S}=\frac{720 R}{{\sqrt{\pi d_{c}^{2} \rho_{0} / 4}}^{-0.72}} .
$$

According to the detonation theory [44], the pressure $\left(P_{G}\right)$ of the detonating gas in the blasthole is

$$
\begin{aligned}
P_{G} & =P_{K}\left(\frac{P_{W}}{P_{K}}\right)^{4 / 9}\left(\frac{V_{\mathrm{c}}}{V_{\mathrm{b}}}\right)^{4 / 3}, \\
P_{W} & =\frac{1}{8} \rho_{0} D^{2}, \\
\rho_{0} V_{\mathrm{c}} & =\rho_{\mathrm{b}} V_{\mathrm{b}}, \\
\rho_{\mathrm{b}} & =\frac{\mathrm{q}}{25 \pi d^{2}},
\end{aligned}
$$

where $P_{K}$ is the critical pressure, $P_{W}$ is the average detonation force, $D$ is the detonation velocity of the explosive, $V_{\mathrm{b}}$ is the blasthole volume, $V_{\mathrm{c}}$ is the charge volume, $\rho_{\mathrm{b}}$ is the charge per unit volume of the blasthole, $q$ is the charge concentration, and $d$ is the borehole diameter.

Combining Eqs. (5), (6), (7), and (8),

$$
P_{G}=P_{K}\left(\frac{\rho_{0} D^{2}}{8 P_{K}}\right)^{4 / 9}\left(\frac{q}{25 \pi d^{2} \rho_{0}}\right)^{4 / 3}
$$




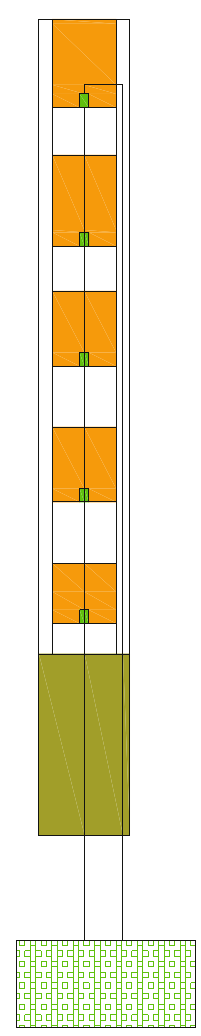

(a)

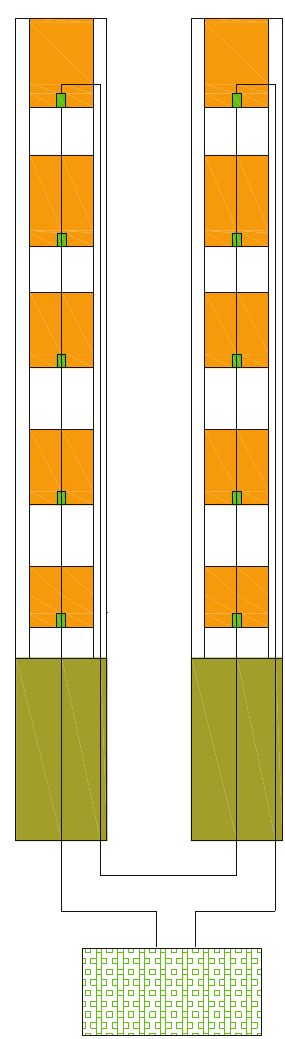

(b)

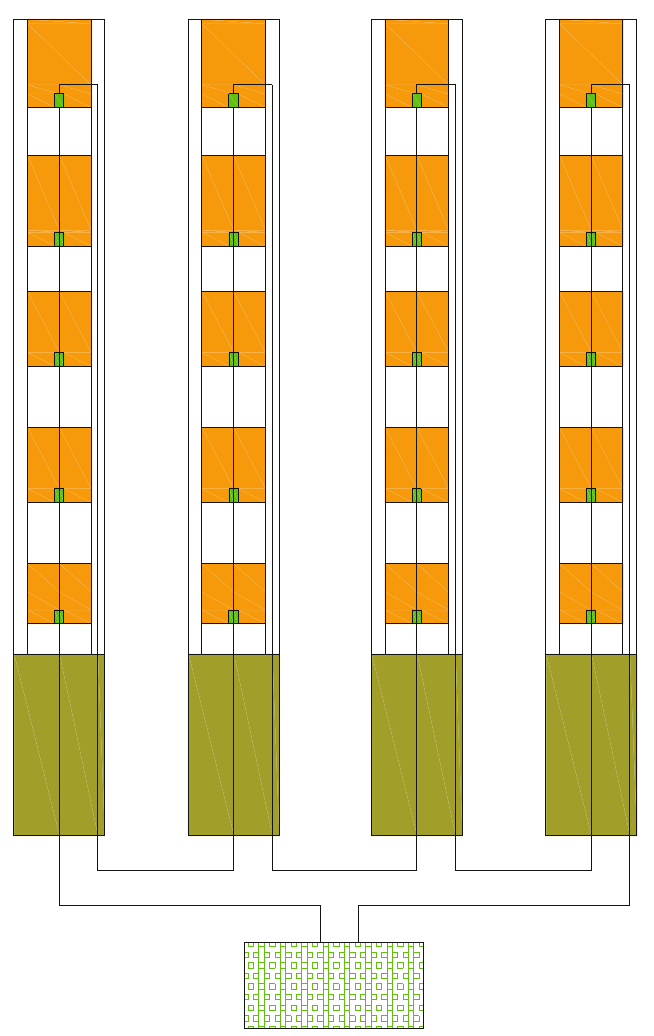

(c)

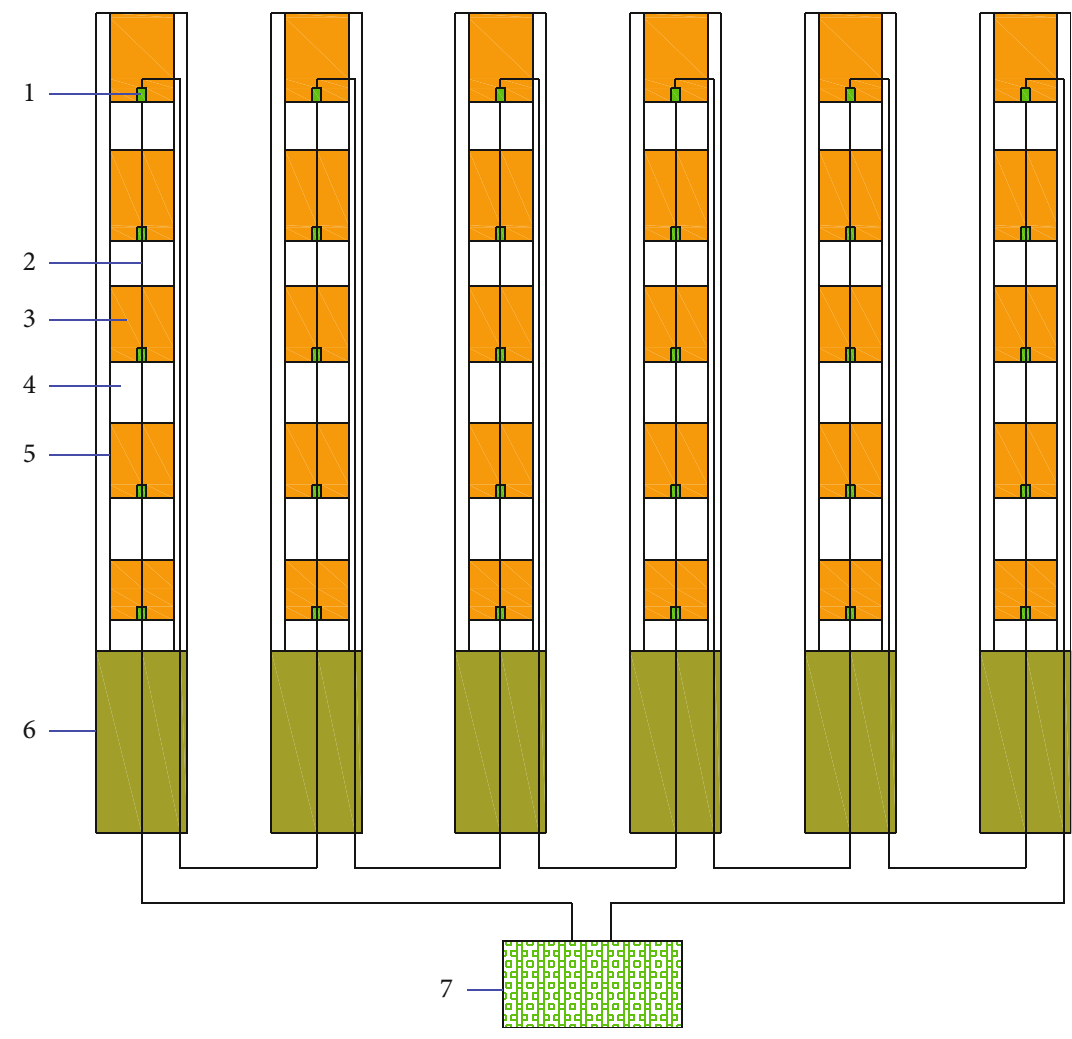

(d)

Figure 7: SCB tests: (a) single hole, (b) double holes, (c) four holes, and (d) six holes (1: detonator; 2: connecting wire; 3: explosive; 4: air; 5: directional slit tube; 6: sealing mud; 7: detonating equipment). 


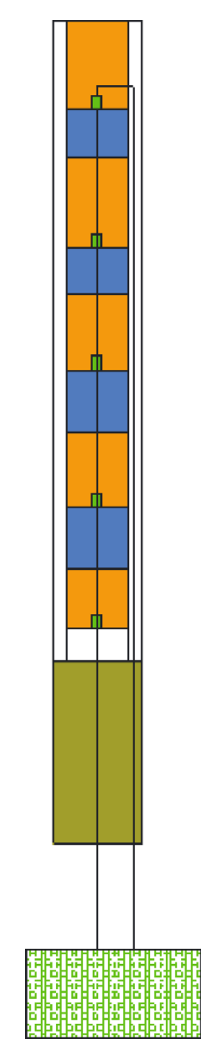

(a)

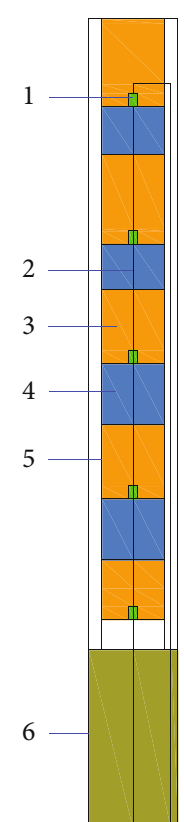

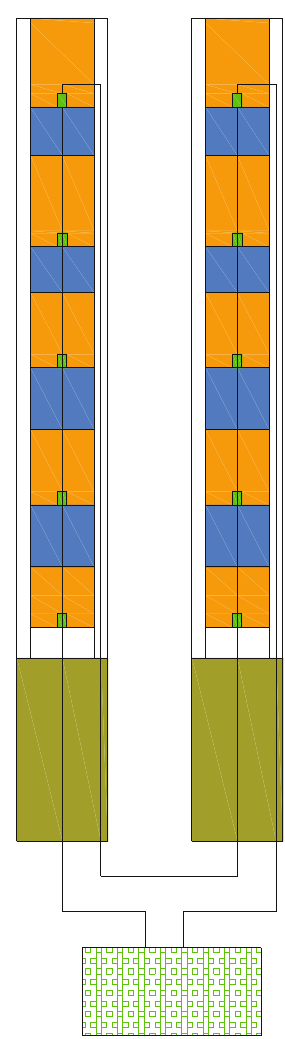

(b)

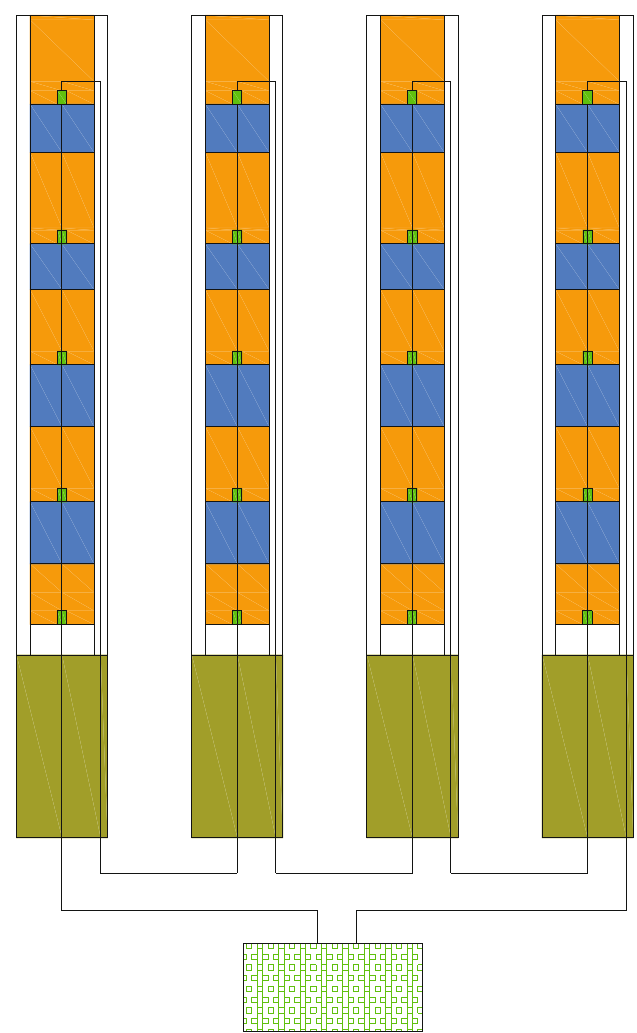

(c)
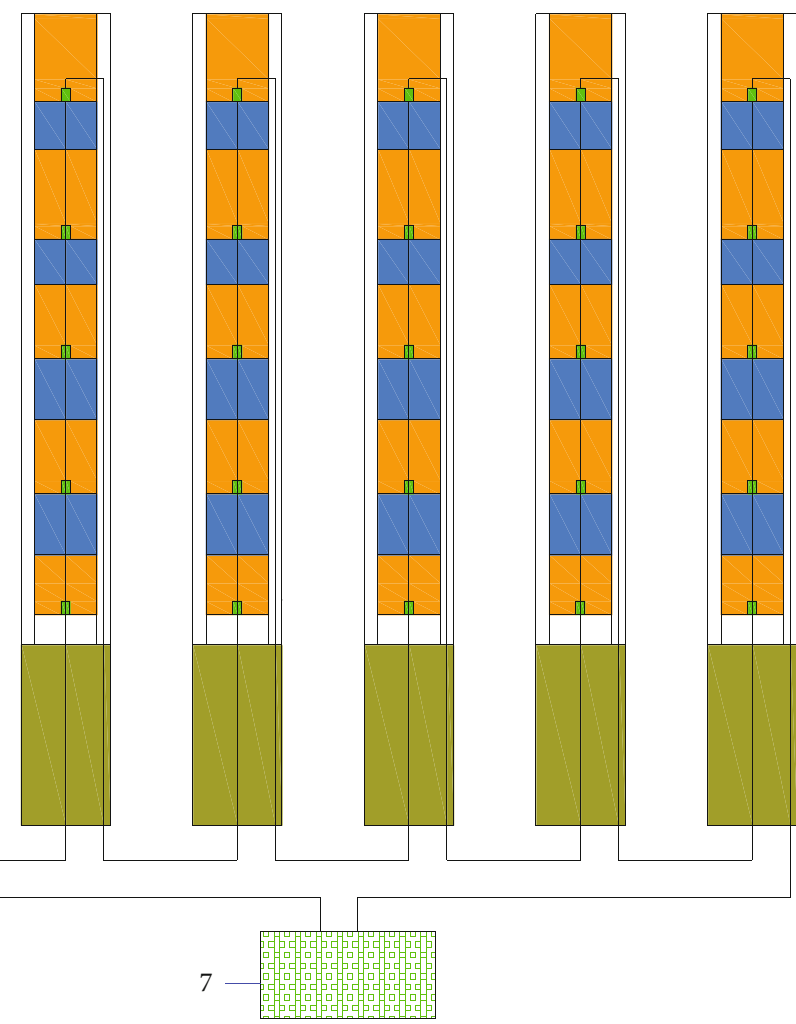

(d)

FIgURE 8: SCHB tests (single-hole charge $4.8 \mathrm{~kg}$ ): (a) single hole, (b) double holes, (c) four holes, and (d) six holes (1: detonator; 2 : connecting wire; 3: explosive; 4: water; 5: directional slit tube; 6: sealing mud; 7: detonating equipment). 


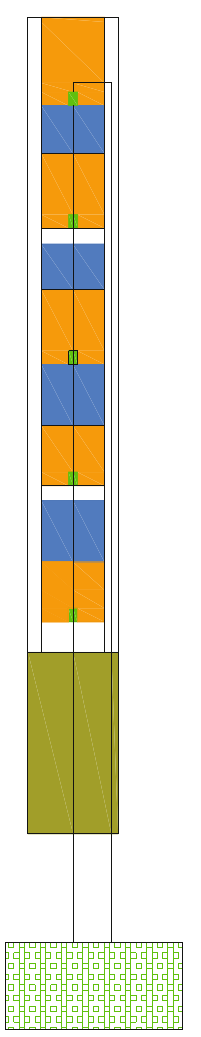

(a)
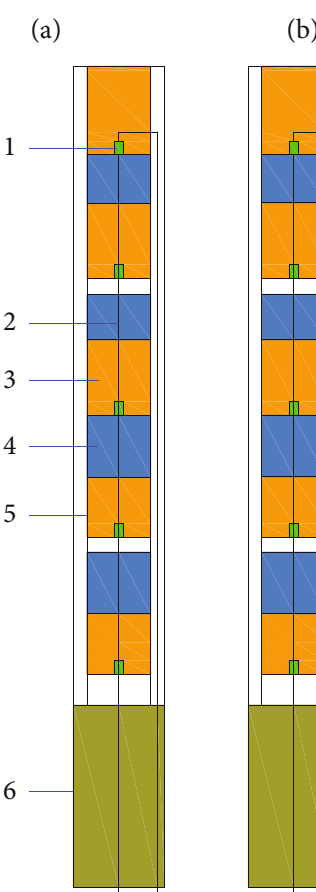

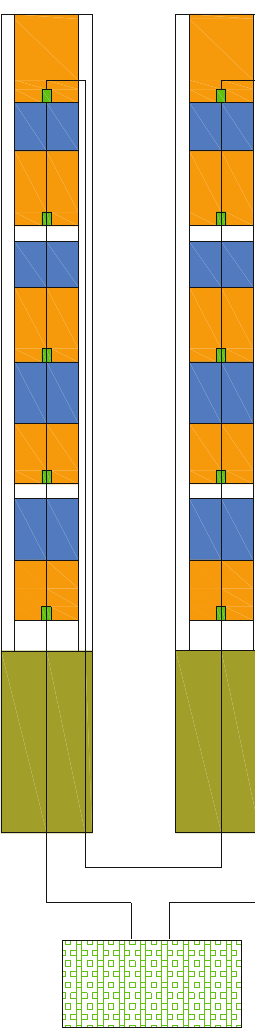

(b)

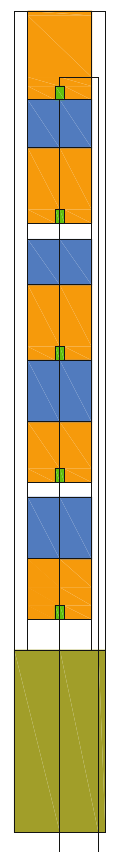

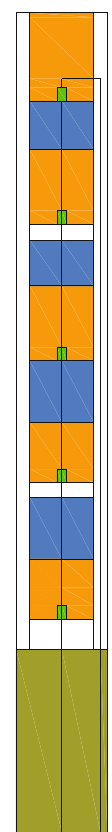
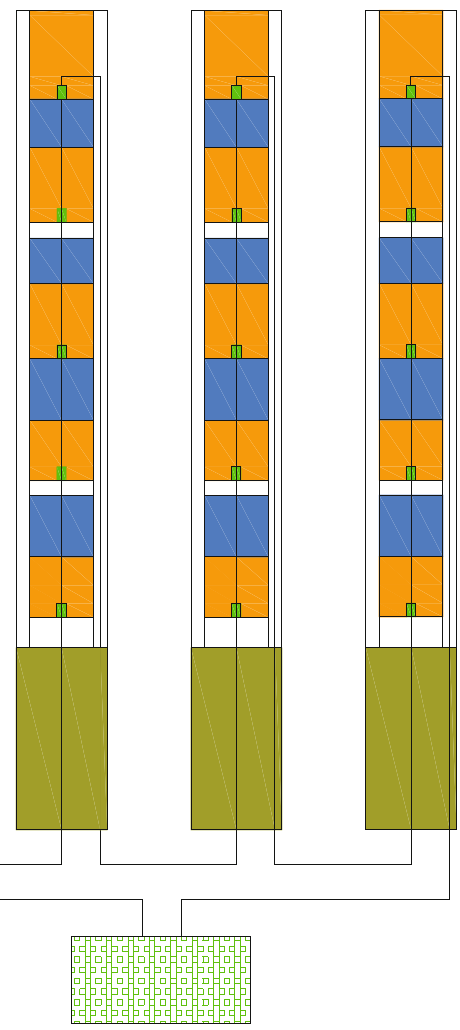

(c)
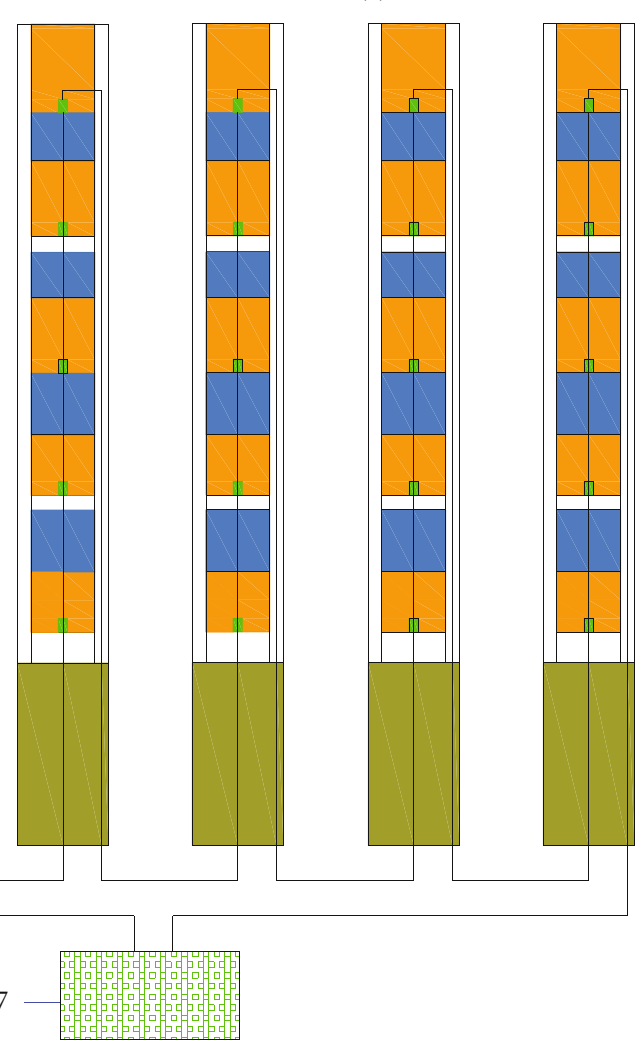

(d)

Figure 9: SCHB tests (single-hole charge $4.2 \mathrm{~kg}$ ): (a) single hole, (b) double holes, (c) four holes, and (d) six holes (1: detonator; 2: connecting wire; 3: explosive; 4: water; 5: directional slit tube; 6: sealing mud; 7: detonating equipment). 
TABLe 2: Designed test scheme.

\begin{tabular}{|c|c|c|c|c|}
\hline Blasting type & One hole charge/kg & $\begin{array}{c}\text { Item } \\
\text { Number of blastholes } \\
\text { at one time }\end{array}$ & $\begin{array}{l}\text { Number of } \mathrm{CO} \\
\text { monitoring sections }\end{array}$ & $\begin{array}{l}\text { Distance of five CO monitoring } \\
\text { sections from blasting zone } / \mathrm{m}\end{array}$ \\
\hline \multirow{4}{*}{ Shaped charge blasting (SCB) } & 4.8 & 1 & 5 & $100-200-300-400-500$ \\
\hline & 4.8 & 2 & 5 & $100-200-300-400-500$ \\
\hline & 4.8 & 4 & 5 & $100-200-300-400-500$ \\
\hline & 4.8 & 6 & 5 & $100-200-300-400-500$ \\
\hline \multirow{4}{*}{$\begin{array}{l}\text { Shaped charge hydraulic } \\
\text { blasting (SCHB) }\end{array}$} & 4.8 & 1 & 5 & $100-200-300-400-500$ \\
\hline & 4.8 & 2 & 5 & $100-200-300-400-500$ \\
\hline & 4.8 & 4 & 5 & $100-200-300-400-500$ \\
\hline & 4.8 & 6 & 5 & $100-200-300-400-500$ \\
\hline \multirow{4}{*}{ SCHB } & 4.2 & 1 & 0 & None \\
\hline & 4.2 & 2 & 0 & None \\
\hline & 4.2 & 4 & 0 & None \\
\hline & 4.2 & 6 & 0 & None \\
\hline
\end{tabular}

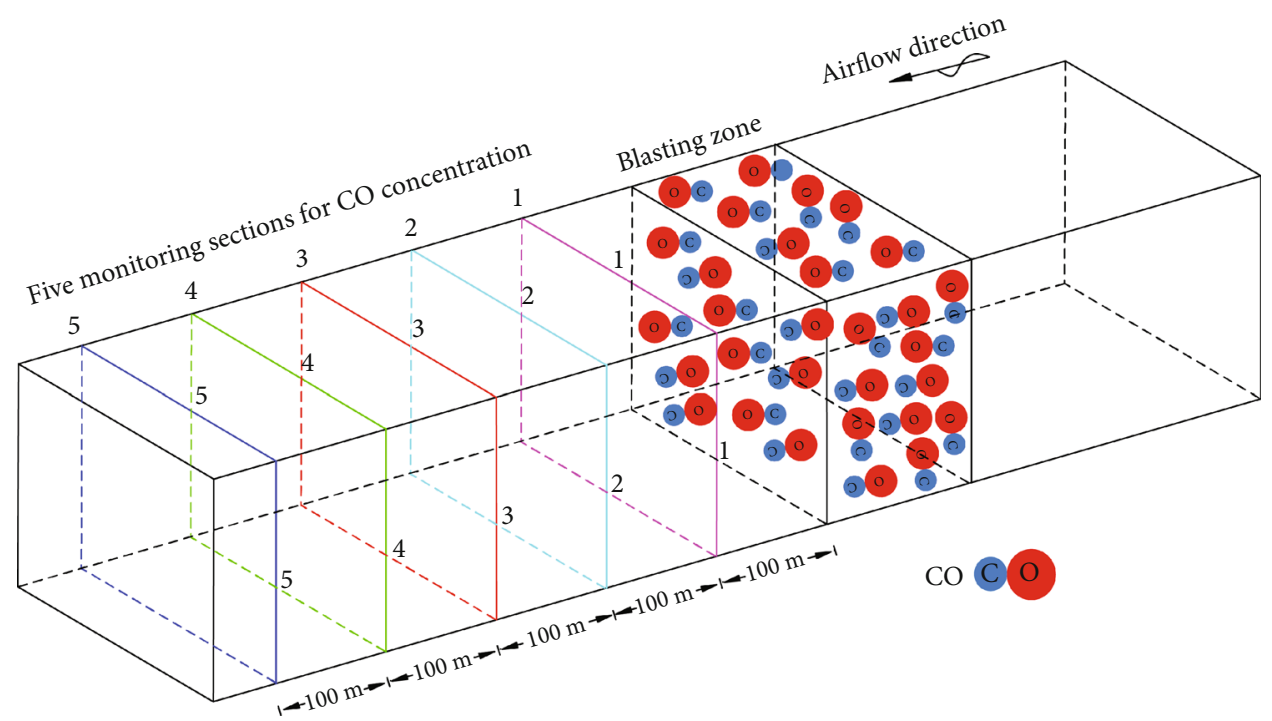

FIGURE 10: Monitoring sections of CO concentration in lane 9-2042: 1-100 $\mathrm{m}$ from blasting zone, 2-200 $\mathrm{m}$ from blasting zone, 3-300 $\mathrm{m}$ from blasting zone, 4-400 $\mathrm{m}$ from blasting zone, and 5-500 $\mathrm{m}$ from blasting zone.

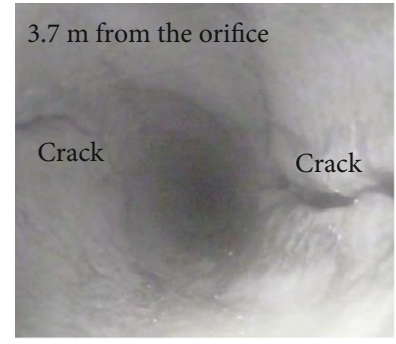

(a)

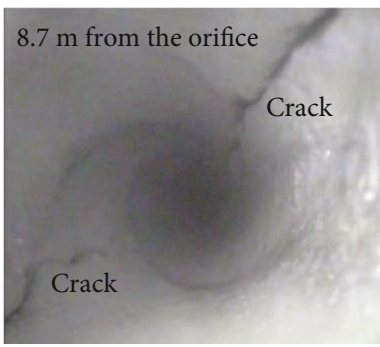

FIGURE 11: Effect of on-site directional roof cutting: (a) SCB and (b) SCHB.
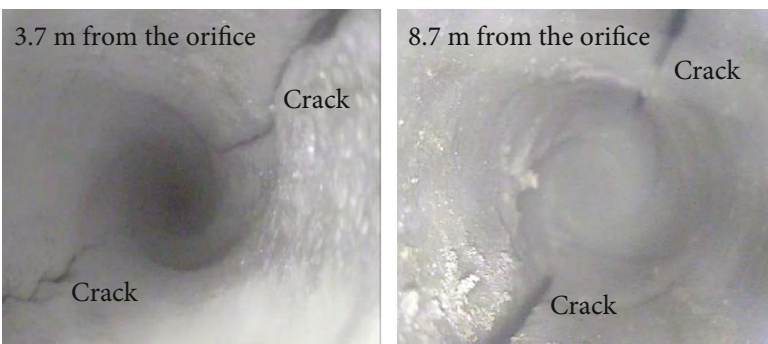

(b)
The pressure $\left(P_{W}\right)$ of the water jet [45] is

$$
P_{W}=\rho_{w} Q u,
$$

where $\rho_{w}$ is the density of water, $Q$ is the flow rate of the water jet, and $u$ is the velocity of the jet.
The water jet velocity is

$$
u=\frac{d_{c}^{2} \rho_{e}}{d_{t}^{2} \rho_{w}+d_{c}^{2}\left(\rho_{e}-\rho_{w}\right)},
$$


TABLE 3: The crack rates of the 13 blastholes in SCB.

\begin{tabular}{|c|c|c|c|c|c|c|c|c|c|c|c|c|c|}
\hline Hole number & 1 & 2 & 3 & 4 & 5 & 6 & 7 & 8 & 9 & 10 & 11 & 12 & 13 \\
\hline Crack length on one side of the hole/m & 5.81 & 5.95 & 6.09 & 5.67 & 5.81 & 5.88 & 6.30 & 5.61 & 5.95 & 5.74 & 6.16 & 5.60 & 6.09 \\
\hline Crack rate & $83 \%$ & $85 \%$ & $87 \%$ & $81 \%$ & $83 \%$ & $84 \%$ & $90 \%$ & $80 \%$ & $85 \%$ & $82 \%$ & $88 \%$ & $80 \%$ & $87 \%$ \\
\hline
\end{tabular}

TABLE 4: The crack rates of the 13 blastholes in SCHB.

\begin{tabular}{|c|c|c|c|c|c|c|c|c|c|c|c|c|c|}
\hline Hole number & 1 & 2 & 3 & 4 & 5 & 6 & 7 & 8 & 9 & 10 & 11 & 12 & 13 \\
\hline Crack length on one side of the hole/m & 6.51 & 6.23 & 6.72 & 6.16 & 6.09 & 6.65 & 6.79 & 6.37 & 6.44 & 5.95 & 6.44 & 6.72 & 6.65 \\
\hline Crack rate & $93 \%$ & $89 \%$ & $96 \%$ & $88 \%$ & $87 \%$ & $95 \%$ & $97 \%$ & $91 \%$ & $92 \%$ & $85 \%$ & $92 \%$ & $96 \%$ & $95 \%$ \\
\hline
\end{tabular}

TABLE 5: Comparison of crack rate between SCB and SCHB.

\begin{tabular}{lccc}
\hline Blasting category & $\begin{array}{c}\text { Amount of } \\
\text { charge in a hole }\end{array}$ & $\begin{array}{c}\text { Average } \\
\text { crack rate }\end{array}$ & $\begin{array}{c}\text { Increased } \\
\text { crack rate }\end{array}$ \\
\hline SCB & $4.8 \mathrm{~kg}$ & $84 \%$ & - \\
SCHB & $4.8 \mathrm{~kg}$ & $92 \%$ & $8 \%$ \\
\hline
\end{tabular}

TABLE 6: Comparison of explosive dosage between SCB and SCHB.

\begin{tabular}{lccc}
\hline Blasting category & $\begin{array}{c}\text { Amount of } \\
\text { charge in a hole }\end{array}$ & $\begin{array}{c}\text { Average } \\
\text { crack rate }\end{array}$ & Save explosives \\
\hline SCB & $4.8 \mathrm{~kg}$ & $84 \%$ & - \\
SCHB & $4.2 \mathrm{~kg}$ & $85 \%$ & $12.5 \%$ \\
\hline
\end{tabular}

where $d_{t}$ is the outer diameter of the directional slit tube and $\rho_{e}$ is the density of the detonation product.

Combining Eqs. (10) and (11),

$$
P_{W}=\rho_{w} Q \frac{d_{c}^{2} \rho_{e}}{d_{t}^{2} \rho_{w}+d_{c}^{2}\left(\rho_{e}-\rho_{w}\right)} .
$$

In summary, the stress $P$ at the crack is

$$
\begin{aligned}
P= & P_{S}+P_{G}+P_{W}=\frac{720 R}{\sqrt{\pi d_{c}^{2} \rho_{0} / 4}-0.72} \\
& +P_{K}\left(\frac{\rho_{0} D^{2}}{8 P_{K}}\right)^{4 / 9}\left(\frac{q}{25 \pi d^{2} \rho_{0}}\right)^{4 / 3} \\
& +\rho_{w} Q \frac{d_{c}^{2} \rho_{e}}{d_{t}^{2} \rho_{w}+d_{c}^{2}\left(\rho_{e}-\rho_{w}\right)}
\end{aligned}
$$

\section{SCHB Directional Roof-Cutting Tests}

3.1. Test Site. Dianping Coal Mine is located in Dianping Village, Dawu Town, Fangshan County, Luliang City, Shanxi Province, China (Figure 3 ). It is a low-gas mine. The coal dust in each coal seam has the danger of explosion, and all coal seams are spontaneously ignited. The test site was the 92042 return air lane of the 9-204 coal mining face. The 92041 roadway was formed automatically by roof cutting in the 9-202 working face. The length of the 9-2042 reserved lane was $1,644 \mathrm{~m}$, and the test was from $500 \mathrm{~m}$ to $1000 \mathrm{~m}$ away from the open-off cut. The cross section of 9-2042 roadway was rectangular, $4.6 \mathrm{~m}$ long, and $3.1 \mathrm{~m}$ high. 9-204 working face adopted $\mathrm{W}$-type ventilation. The wind speed was $1.8 \mathrm{~m} / \mathrm{s}$, and the air volume flow rate was $350 \mathrm{~m}^{3} / \mathrm{min}$. The return air shaft was $530 \mathrm{~m}$ away from the test site.

3.2. Test Scheme. The SCB and SCHB tests were performed in the 9-2042 lanes. The immediate roof above the coal seam was mudstone, and the main roof was fine sandstone. The mechanical parameters of the roof rock are shown in Table 1. The roof-cutting depth was $9 \mathrm{~m}$, and the angle between the blastholes and the vertical direction was $17^{\circ}$ (Figure 4). The charge structure of SCB is shown in Figure 5. The length of the sealed hole was $2 \mathrm{~m}$, and the total length of the directional slit tube was $7 \mathrm{~m}$. There were a total of five directional slit tubes with lengths of $1.5 \mathrm{~m}, 1.5 \mathrm{~m}$, $1.5 \mathrm{~m}, 1.5 \mathrm{~m}$, and $1 \mathrm{~m}$. The five tubes were loaded with charges that weight $1.2 \mathrm{~kg}, 1.2 \mathrm{~kg}, 0.9 \mathrm{~kg}, 0.9 \mathrm{~kg}$, and $0.6 \mathrm{~kg}$, and a single-hole charge weighed $4.8 \mathrm{~kg}$. An explosive roll was $300 \mathrm{~mm}$ long, $35 \mathrm{~mm}$ in diameter, and weighed $0.3 \mathrm{~kg}$. The directional slit tube had an inner diameter of $36.5 \mathrm{~mm}$, an outer diameter of $42 \mathrm{~mm}$, and a hole diameter of $48 \mathrm{~mm}$.

As shown in Figure 6, there are two types of SCHB charge structure. The first structure has a single-hole charge of $4.8 \mathrm{~kg}$ and five directional slit tubes with charges of $1.2 \mathrm{~kg}, 1.2 \mathrm{~kg}$, $0.9 \mathrm{~kg}, 0.9 \mathrm{~kg}$, and $0.6 \mathrm{~kg}$. The other has a single-hole charge of $4.2 \mathrm{~kg}$ with charge amounts of $1.2 \mathrm{~kg}, 0.9 \mathrm{~kg}, 0.9 \mathrm{~kg}$, $0.6 \mathrm{~kg}$, and $0.6 \mathrm{~kg}$. Compared with the charge structure of SCB, SCHB uses water bags in the directional slit tubes. The rest of the conditions were the same as SCB's. Both types of SCHB used 1, 4, 3, and 3 water bags in four directional slit tubes, respectively. The last tube was not put into the water bag, so as not to damage the water bag when loading the gun mud. In single-hole SCB (Figure 7(a)), double-hole SCB (Figure 7(b)), four-hole SCB (Figure 7(c)), and sixhole SCB (Figure $7(\mathrm{~d})$ ), the charge structures of all holes are the same. In single-hole SCHB (Figures 8(a) and 9(a)), double-hole SCHB (Figures 8(b) and 9(b)), four-hole SCHB (Figures 8(c) and 9(c)), and six-hole SCHB (Figures 8(d) and $9(\mathrm{~d})$ ), the charge structures of all holes are the same.

SCHB tests with a hole charge of $4.8 \mathrm{~kg}$ were conducted for comparing the results with the directional roof-cutting effect, crack rate, and CO gas concentration of the SCB tests. SCHB tests with a hole charge of $4.2 \mathrm{~kg}$ were used for comparing the results to those with the SCB explosive charge. 


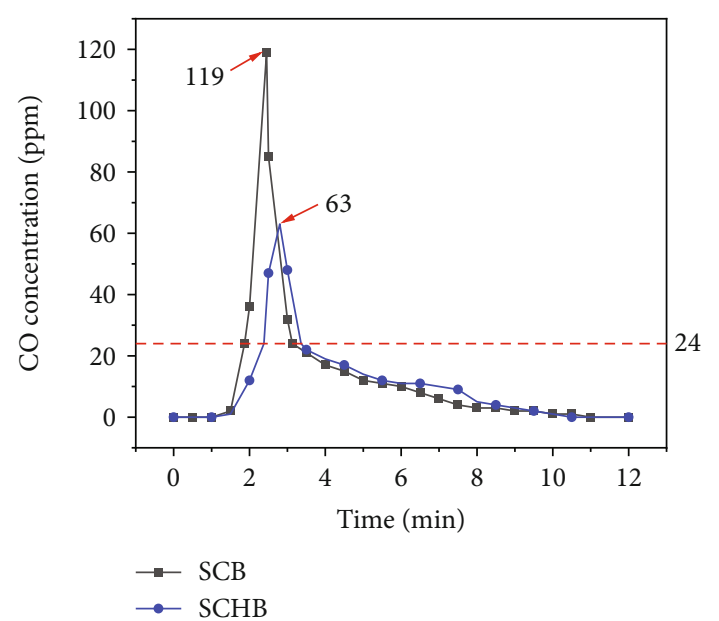

(a)

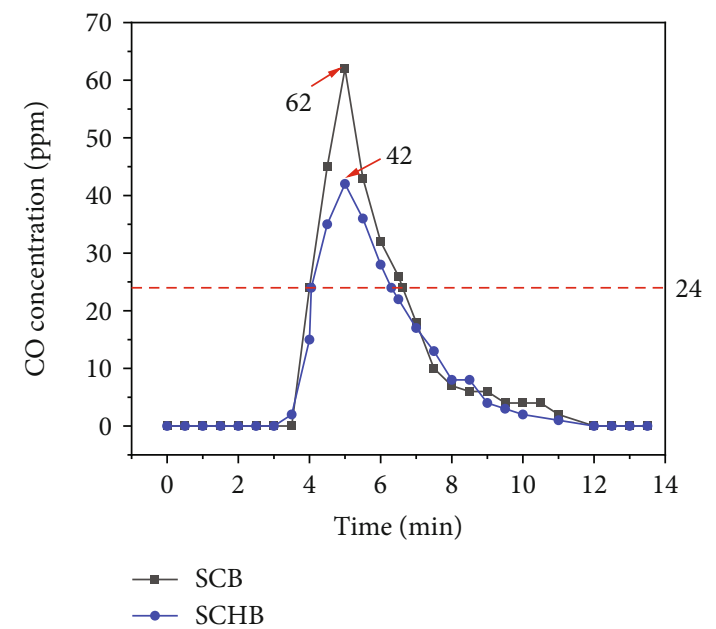

(c)

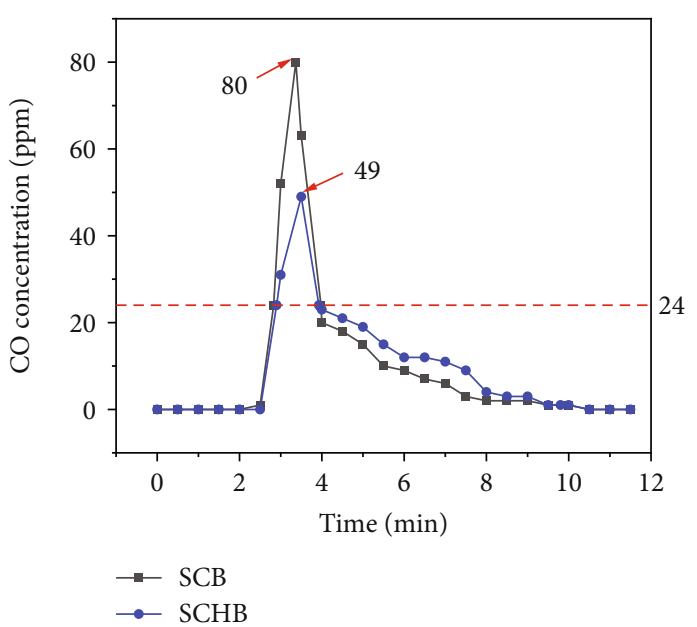

(b)

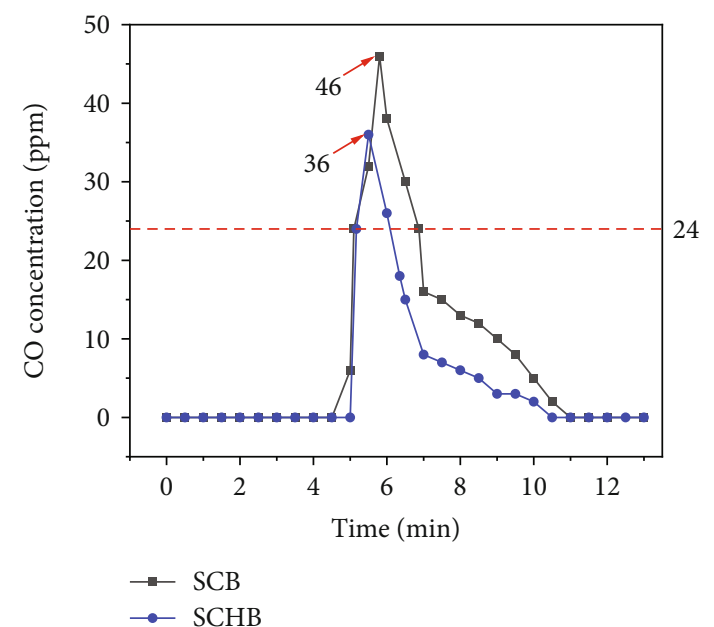

(d)

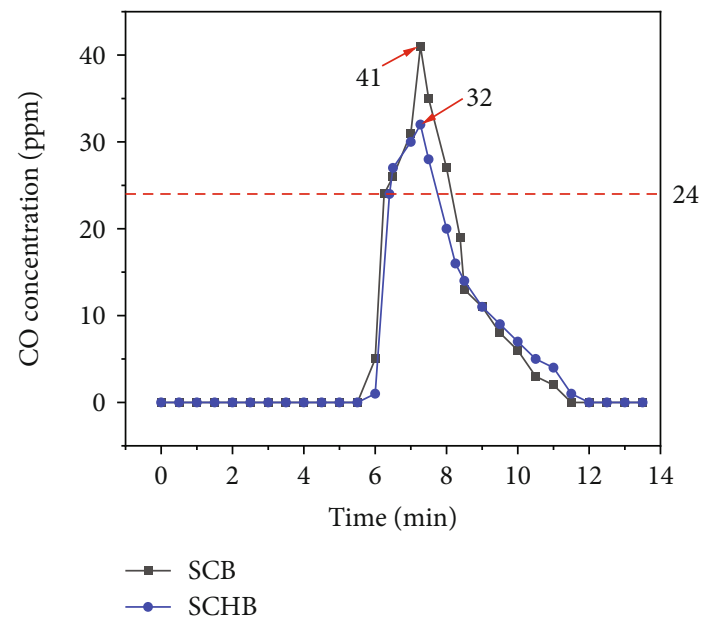

(e)

FIGURE 12: Time-varying curve of CO concentration in single-hole blasting at different measuring points: (a) $100 \mathrm{~m}$ from blasting zone, (b) $200 \mathrm{~m}$ from blasting zone, (c) $300 \mathrm{~m}$ from blasting zone, (d) $400 \mathrm{~m}$ from blasting zone, and (f) $500 \mathrm{~m}$ from blasting zone.

In the single-hole, double-hole, four-hole, six-hole SCB, and SCHB (one-hole charge was $4.8 \mathrm{~kg}$ ) test processes, five roadway sections monitored $\mathrm{CO}$ concentration (Table 2). Five CO concentration monitoring sections were at distances of $100 \mathrm{~m}, 200 \mathrm{~m}, 300 \mathrm{~m}, 400 \mathrm{~m}$, and $500 \mathrm{~m}$ from the blasting zone (Figure 10). A test point was arranged on each section. 


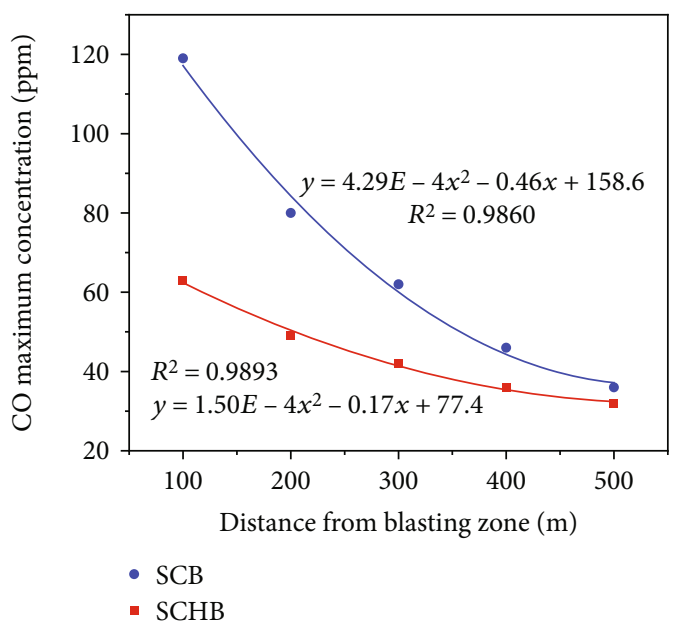

FIgURE 13: Changes in maximum $\mathrm{CO}$ concentration with monitoring distance in single-hole SCB and SCHB.

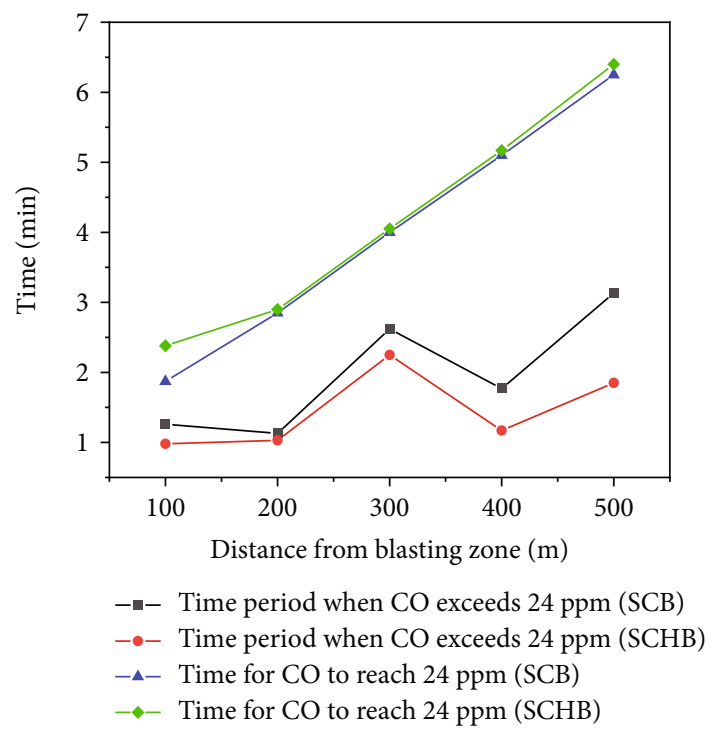

FIGURE 14: Time taken by $\mathrm{CO}$ to reach $24 \mathrm{ppm}$ and exceed the same along the monitoring distance in single-hole SCB and SCHB.

Before and after the tests, the borehole peeper was used to observe cracks in the hole, and the crack rates of the two blasting methods were compared and analyzed.

3.3. Test Process. A row of holes was drilled in the roof, and then, the explosives were loaded into the directional slit tubes. Water bags were placed in the directional slit tubes during the SCHB test. The tubes were then put into the boreholes, and the shape charge holes of the directional slit tubes were oriented along the direction of directional presplitting. After the five directional slit tubes filled with explosives were filled in the drill holes, the holes were sealed with gun mud. When sealing the holes, the gun mud was tamped to prevent the explosives from breaking away and influencing the blasting effect. After the charge loading was completed, the blastholes were detonated. At the time of detonation, the $\mathrm{CO}$ concentration detectors at distances of $100 \mathrm{~m}, 200 \mathrm{~m}, 300 \mathrm{~m}$, $400 \mathrm{~m}$, and $500 \mathrm{~m}$ from the blasting site needed to be turned on simultaneously to record the CO concentration data. In addition, the dust concentration was monitored at a distance of $300 \mathrm{~m}$ from the blasting area. Furthermore, a peeper was used to observe the cracks in the holes before and after the tests.

\section{Test Results and Discussion}

4.1. Directional Roof-Cutting Effect. Before the blast, there were no cracks in the hole. The cracks generated by SCB and SCHB after the blast are shown in Figures 11(a) and 11(b), respectively. Neither blasting methods could break the hole wall. There were, however, two cracks in it. Both could achieve the effect of directional roof cutting. This was because, whether it was SCB or SCHB, the orientation effect was achieved by the directional slit tube. The directional slit tube changed the balance of impact of the shock wave on the hole wall in the initial stage. Therefore, energy from the shock wave was mainly concentrated in the direction of the two rows of shape charge holes, and tangential tensile stress was formed on the hole wall. The initial cracks were formed when the tensile stress at the hole wall exceeded the dynamic tensile strength of the rock. Subsequently, when the stress intensity factor at the crack tip was greater than the dynamic fracture toughness of the rock, the crack expanded in a predetermined direction.

SCB relied on the air medium to couple. SCHB's coupling medium was mainly water and a small amount of air. The SCB rock-breaking mechanism used shock wave and gas pressure, while the SCHB rock-breaking mechanism has three modes-shock wave, gas pressure, and water pressure. Although SCHB had more water wedges than SCB, and it was less destructive, these waves and forces were still mainly concentrated in the direction of the shape charge holes, and the rock mass in the other directions was protected by the energy-gathering pipes. Therefore, the crack-propagation direction of the rock mass in the two blasting modes was the same, and the directional effect was independent of the coupling medium.

4.2. Crack Rate. The crack ratio is the ratio of the length of the crack generated on one side of the borehole to the length of the directional slit tubes. The self-forming roadway without coal pillars required that the cutting rate be no less than $80 \%$. The crack rates of the 13 blastholes in SCB were $83 \%$, $85 \%, 87 \%, 81 \%, 83 \%, 84 \%, 90 \%, 80 \%, 85 \%, 82 \%, 88 \%, 80 \%$, and $87 \%$ (Table 3 ). The average crack rate was $84 \%$. The crack rates in thirteen boreholes in SCHB were 93\%, 89\%, $96 \%, 88 \%, 87 \%, 95 \%, 97 \%, 91 \%, 92 \%, 85 \%, 92 \%, 96 \%$, and $95 \%$ (Table 4). The average crack rate was $92 \%$. Although the two blasting methods have the same charge, the SCHB replaced part of the air medium with water, and the crack rate was increased by $8 \%$.

The increase in crack rate was conducive to the timely collapse of the roof along the cutting line, optimized the stress environment, reduced the support resistance of the roadway behind the working face, and weakened the roadway 


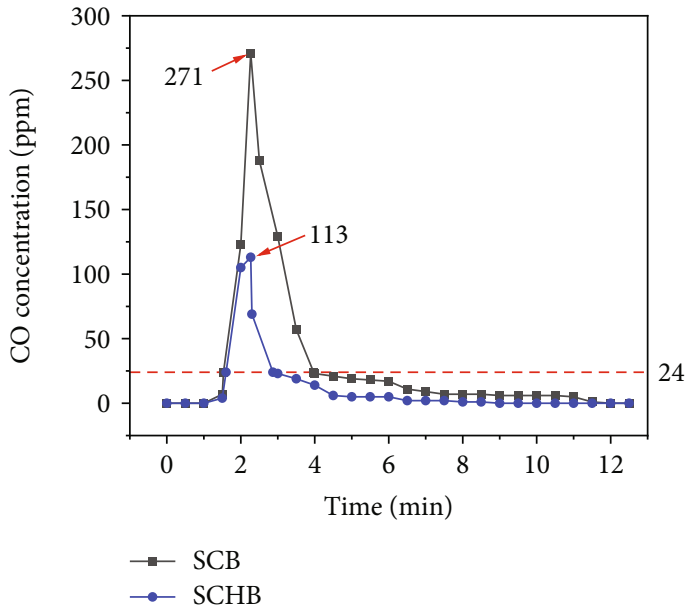

(a)

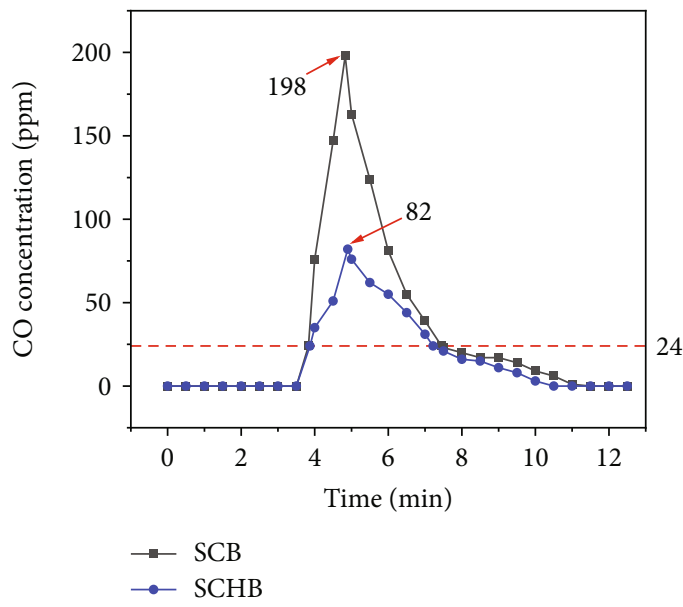

(c)

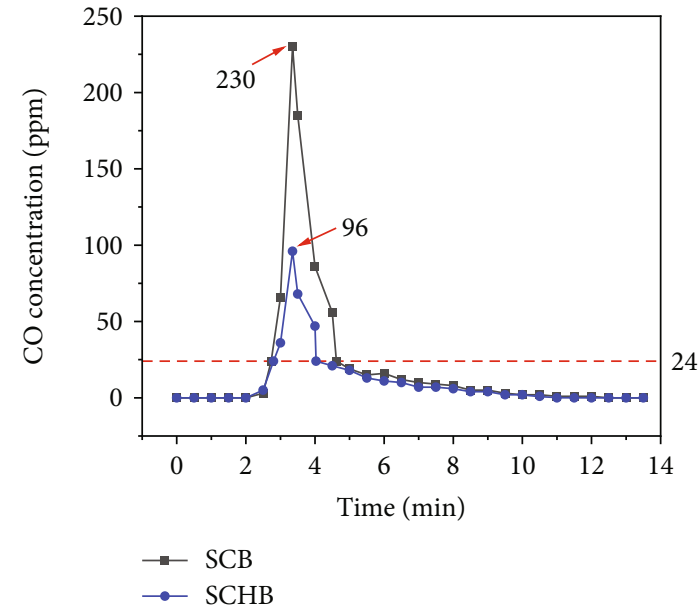

(b)

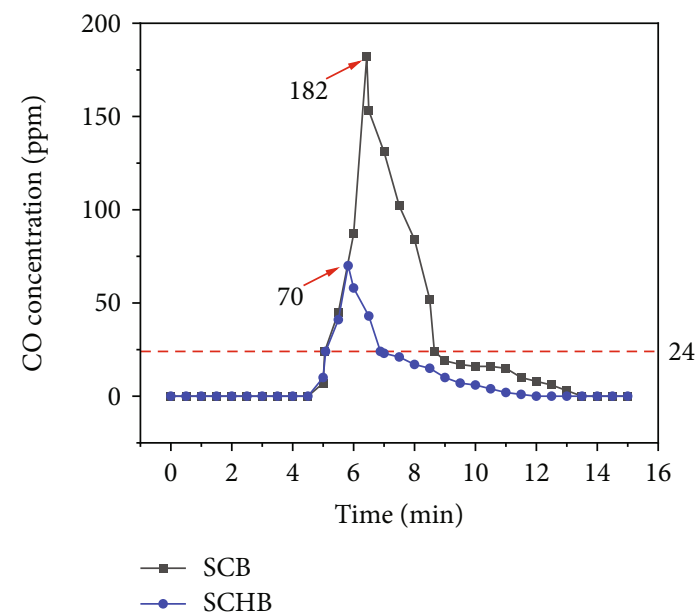

(d)

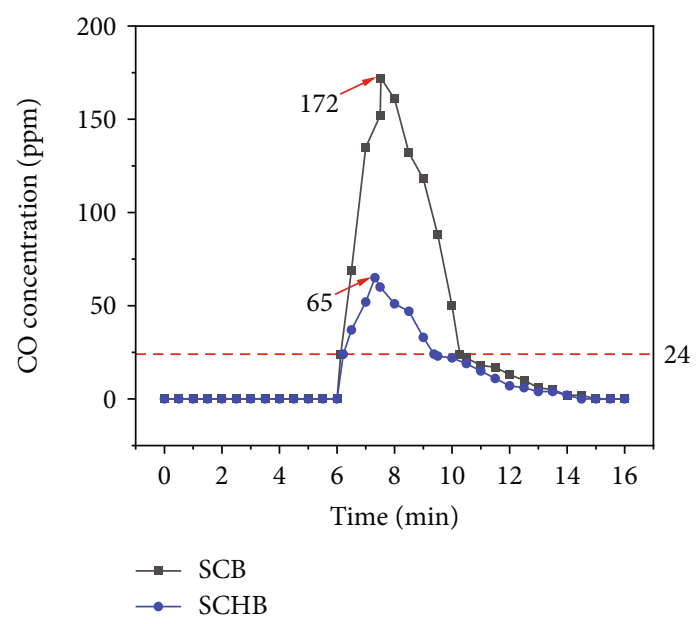

(e)

FIGURE 15: Time-varying curve of CO concentration in double-hole blasting at different measuring points: (a) $100 \mathrm{~m}$ from blasting zone, (b) $200 \mathrm{~m}$ from blasting zone, (c) $300 \mathrm{~m}$ from blasting zone, (d) $400 \mathrm{~m}$ from blasting zone, and (f) $500 \mathrm{~m}$ from blasting zone.

deformation. The power of explosives in water was much greater than that in air. On the one hand, the intensity of shock waves in water was greater. The initial pressure of the shock wave in the air ranged from 0.8 to $1.3 \mathrm{MPa}$, while reaching $100 \mathrm{MPa}$ in water [46]. Thus, the intensity of the shock wave in water increased by nearly a hundred times. 
On the other hand, the static water instantly became a highspeed water jet after the explosive was detonated, and its impact force on the rock was large. However, the SCB did not exhibit the water wedge effect. Therefore, SCHB had a higher crack rate than SCB, and their comparison is drawn in Table 5.

4.3. Explosive Dosage. Under the condition that the crack rate was no less than $80 \%$, the total charge in a borehole for SCHB was changed to $4.2 \mathrm{~kg}$, to reduce the costs. According to the charge loaded, the crack rates of the 13 blastholes were $85 \%, 86 \%, 88 \%, 83 \%, 87 \%, 80 \%, 81 \%, 91 \%, 86 \%, 89 \%, 82 \%$, $85 \%$, and $87 \%$, and the average crack rate was $85 \%$. This is similar to the crack rate of traditional SCB with a singlehole charge of $4.8 \mathrm{~kg}$. Therefore, to achieve the same roofcutting effect, the charge of SCHB weighed less than that of traditional SCB, which could save $12.5 \%$ of the explosive charge (Table 6).

There are two ways in which SCHB saves explosive mass. (1) Due to the low compressibility and high density of water, the peak pressure of the shock wave generated by the detonation of the same amount of explosive in water was much higher than in air. SCHB could produce a large impact force on the hole wall. In addition, the expansion rate of the water explosion products was slower than that in air, so the quasistatic stress field formed by SCHB took a long time to act [47]. Therefore, water coupling increases the stress at the crack tip and prolongs the time of effect of crack propagation. As a result, the length of crack propagation and the blasthole spacing increased. (2) SCHB increased the rockbreaking effect of high-speed water jets. After the explosion, the water in the water bag was ejected at an extremely high velocity along the energy gathering holes. When the highspeed water jet speed reached $500 \mathrm{~m} / \mathrm{s}$, the impact pressure was about $300 \mathrm{MPa}$. Moreover, $14 \mathrm{mg}$ of explosives exploded in water, resulting in a jet velocity of $700 \mathrm{~m} / \mathrm{s}$ [48]. The charge of this test was $4.2 \mathrm{~kg}$, so its impact force was greater.

4.4. Economic Cost. The length of this roadway was $1,644 \mathrm{~mm}$. The SCB had a blasthole spacing of $400 \mathrm{~mm}$, a number of blastholes of 4,110 , and required $19,828 \mathrm{~kg}$ of explosives. The distance between adjacent blastholes for SCHB was $500 \mathrm{~mm}$, the number of blastholes was 3288, and $13810 \mathrm{~kg}$ of explosives was required. Therefore, the entire tunnel saved $5918 \mathrm{~kg}$ of explosives. If the explosive price was $20 \mathrm{RMB} / \mathrm{kg}$, it could save $118,360 \mathrm{RMB}$. The number of drill holes for SCHB was 822 less than that of SCB, which saved about 130,000 RMB in labor cost and improved construction efficiency. The total cost of the water bag for the SCHB was about 3500 RMB. Therefore, the SCHB technology has saved this roadway $127,860 \mathrm{RMB}$. In summary, the SCHB could greatly save the amount of explosives, reduce the economic cost, and improve the operation efficiency.

\subsection{CO Concentration}

4.5.1. Single-Hole Blasting. The CO concentration of SCB and $\mathrm{SCHB}$ at $100 \mathrm{~m}, 200 \mathrm{~m}, 300 \mathrm{~m}, 400 \mathrm{~m}$, and $500 \mathrm{~m}$ from the blasting site changed with time, as shown in Figure 12. All the five monitoring points indicated that the $\mathrm{CO}$ concentra-

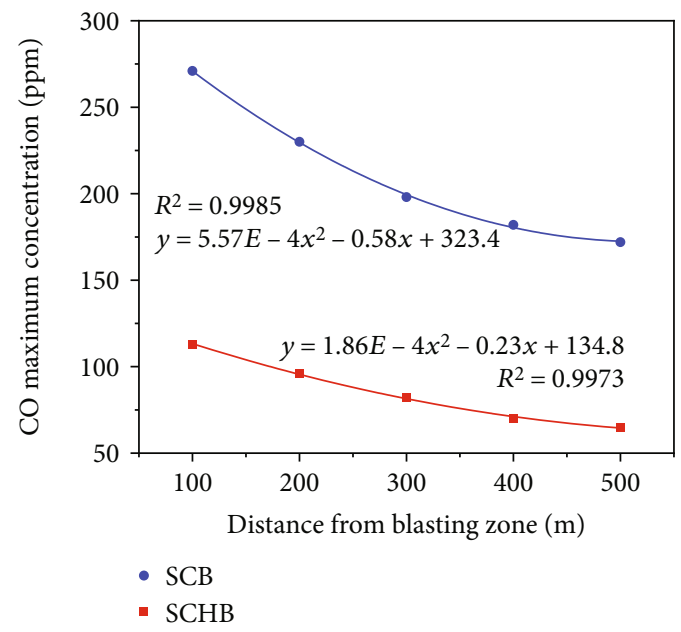

Figure 16: Changes in maximum $\mathrm{CO}$ concentration with monitoring distance in double-hole SCB and SCHB.

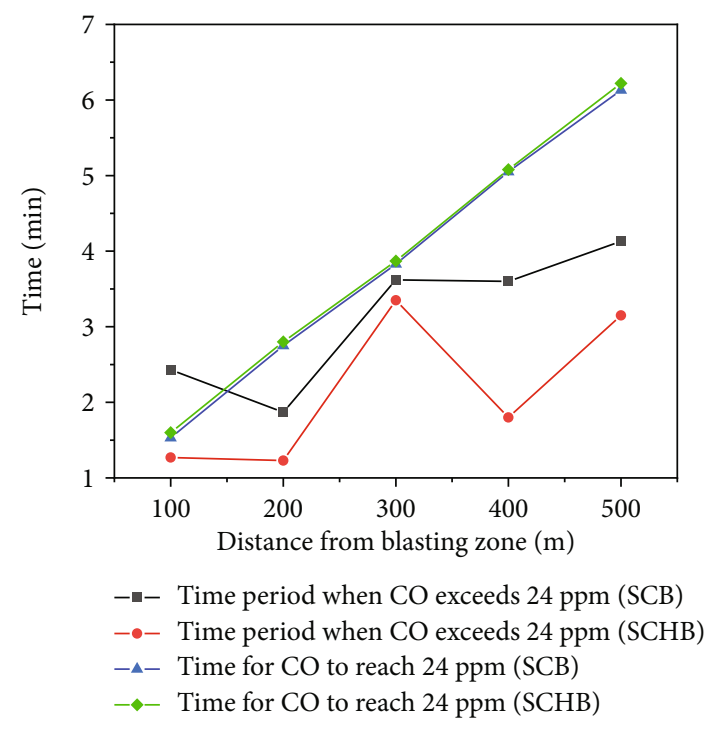

Figure 17: Time taken by CO to reach $24 \mathrm{ppm}$ and exceed the same with the monitoring distance in double-hole SCB and SCHB.

tion was divided into the normal stage, the rapid increase stage, the sharp decline stage, the slow decline stage, and returning-to-the-normal stage. After the blasting, it took a while for $\mathrm{CO}$ to reach the monitoring location. Before $\mathrm{CO}$ reached the monitoring point, its concentration at the monitoring point was the same as before the blasting (normal level). This period was called the normal stage. After reaching the monitoring point, its concentration rose rapidly to the highest possible value. This stage was called the rapid increase stage. Beyond this value, the concentration of CO decreased rapidly, which was called the sharp decline stage. When the concentration of $\mathrm{CO}$ dropped to a certain value, its rate of decline slowed down. This was called the slow decline stage. As fresh air continued to dilute the cannon smoke, the $\mathrm{CO}$ concentration returned to the same size as from before the blast. This was called the return-to-normal stage. 


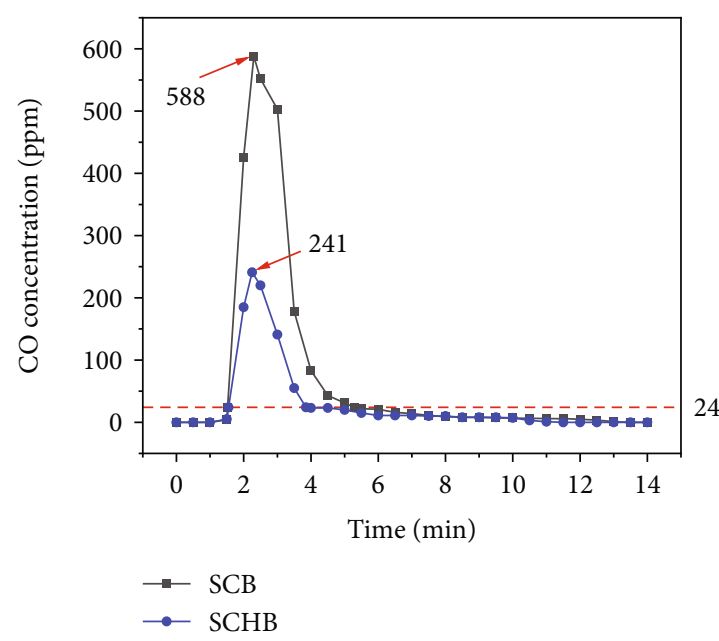

(a)

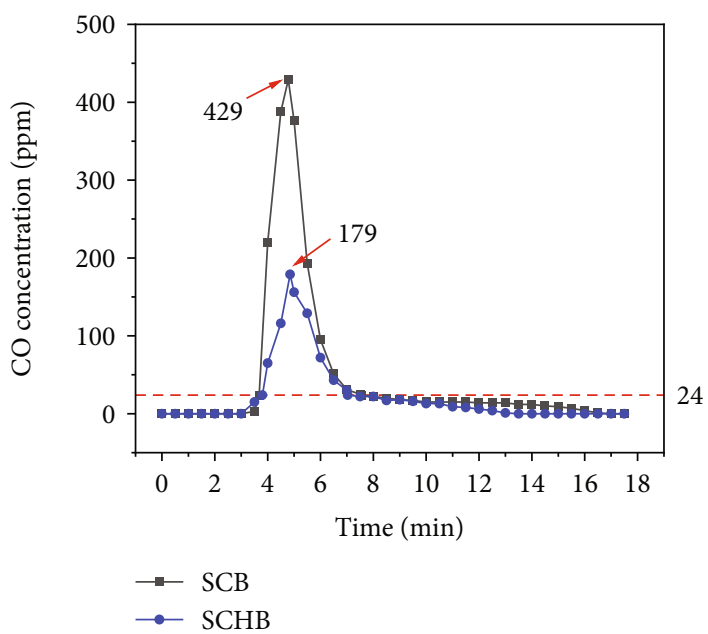

(c)

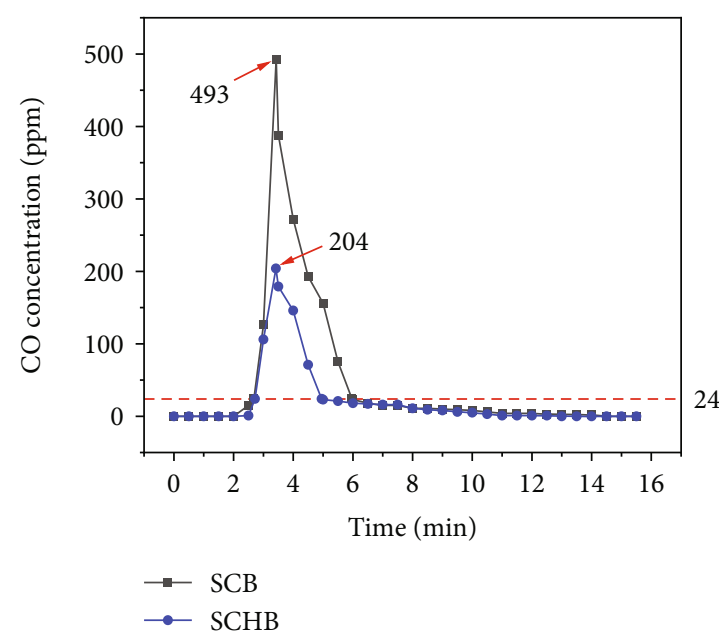

(b)

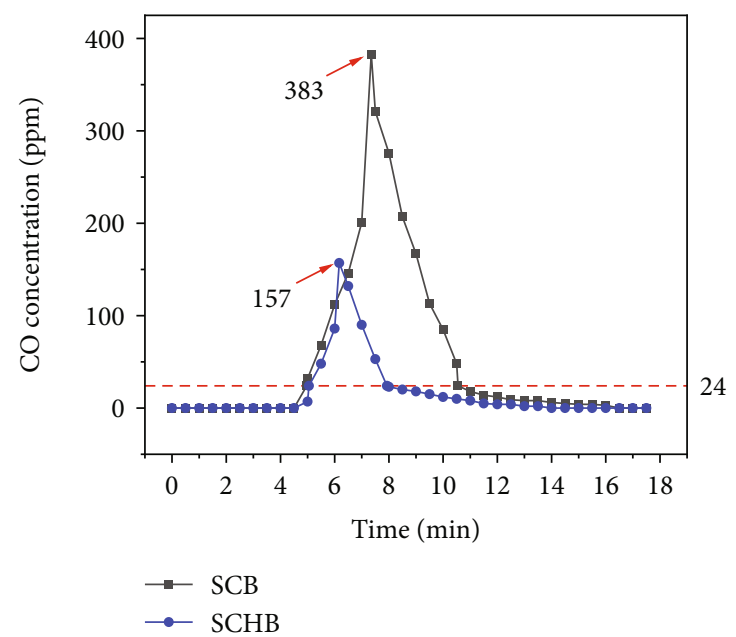

(d)

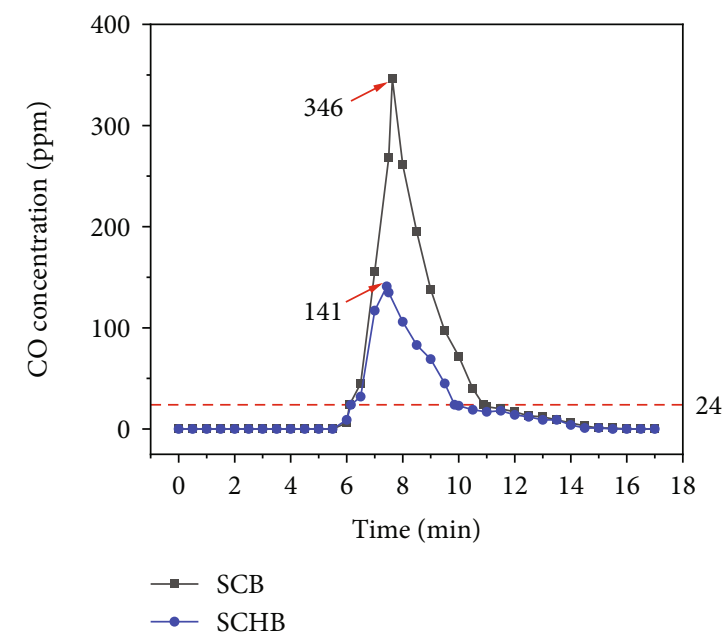

(e)

FIGURE 18: Time-varying curve of CO concentration in four-hole blasting at different measuring points: (a) $100 \mathrm{~m}$ from blasting zone, (b) $200 \mathrm{~m}$ from blasting zone, (c) $300 \mathrm{~m}$ from blasting zone, (d) $400 \mathrm{~m}$ from blasting zone, and (f) $500 \mathrm{~m}$ from blasting zone.

The maximum concentration of $\mathrm{CO}$ in SCB and SCHB showed a parabolic decline with increasing monitoring distance (Figure 13). The CO inhibition rate was introduced to analyze the reduction of $\mathrm{CO}$ concentration after the SCHB. The maximum concentration of $\mathrm{CO}$ at a certain monitoring point for SCB was $M_{1}$. The maximum concentration of $\mathrm{CO}$ 
at the same monitoring point for SCHB was $M_{2}$. Therefore, the CO inhibition rate is

$$
\mu=\frac{M_{1}-M_{2}}{M_{1}} \times 100 \%
$$

The CO inhibition rates at $100 \mathrm{~m}, 200 \mathrm{~m}, 300 \mathrm{~m}, 400 \mathrm{~m}$, and $500 \mathrm{~m}$ were $47 \%, 39 \%, 32 \%, 22 \%$, and $22 \%$, respectively. Therefore, the SCHB could significantly reduce the CO concentration, optimize the working environment, and benefit the health of workers. The threshold limit of CO concentration in China is $24 \mathrm{ppm}$. At different monitoring sites, the SCHB reached $24 \mathrm{ppm}$ after the SCB (Figure 14). Within $100-500 \mathrm{~m}$ of the blasting area, the time taken by the CO concentration to exceed threshold of SCHB was shorter than that in SCB. Moreover, the time taken by the SCB CO concentration to exceed the threshold did not exceed $3.13 \mathrm{~min}$, while the time taken by the SCHB CO concentration to exceed the same did not exceed $2.25 \mathrm{~min}$. Due to the small charge of single-hole blasting, the CO concentration took less time to exceed the threshold. Therefore, $\mathrm{CO}$ entered the blasting area earlier.

4.5.2. Double-Hole Blasting. After the double-hole initiation, the $\mathrm{CO}$ concentration at a monitoring point also went through five stages with time: the normal stage, the rapid increase stage, the sharp decline stage, the slow decline stage, and return-to-normal stage (Figure 15). The total time of hese five stages did not exceed $16 \mathrm{~min}$. Compared with single-hole blasting, the charge amount of doublehole blasting was doubled, so the amount of $\mathrm{CO}$ generated was also higher than that of single-hole blasting at the five monitoring points. The peak value of the $\mathrm{CO}$ concentration decreased with the increase of the monitoring distance, and the peak value decreased rapidly thereafter. At the same moment, in any given location, the $\mathrm{CO}$ concentration produced by the SCHB was not greater than that of the SCB. This shows that the water medium coupling is better than the air medium, which could reduce the percentage of toxic and harmful gases.

The relationship between the maximum $\mathrm{CO}$ concentration and the monitoring distance for $\mathrm{SCB}$ and $\mathrm{SCHB}$ (Figure 16) is

$$
\begin{aligned}
& y=5.57 E-4 x^{2}-0.58 x+323.4 \\
& y=1.86 E-4 x^{2}-0.23 x+134.8
\end{aligned}
$$

At distances of $100 \mathrm{~m}, 200 \mathrm{~m}, 300 \mathrm{~m}, 400 \mathrm{~m}$, and $500 \mathrm{~m}$ from the blasting zone, the maximum $\mathrm{CO}$ concentrations of SCB were $271 \mathrm{ppm}, 230 \mathrm{ppm}, 198 \mathrm{ppm}, 182 \mathrm{ppm}$, and $172 \mathrm{ppm}$, while the maximum CO concentrations of SCHB were 113 ppm, $96 \mathrm{ppm}, 82 \mathrm{ppm}, 70 \mathrm{ppm}$, and $65 \mathrm{ppm}$, respectively. Therefore, the SCHB CO inhibition rates at these five monitoring points were $58 \%, 58 \%, 59 \%, 62 \%$, and $62 \%$, respectively. As shown in Figure 17, the $\mathrm{CO}$ concentration overrun time of SCB was from 1.87 to $4.13 \mathrm{~min}$, and that of $\mathrm{SCHB}$ was between 1.23 and $3.35 \mathrm{~min}$. At the five monitoring points, the $\mathrm{CO}$ concentration overrun time period of SCHB

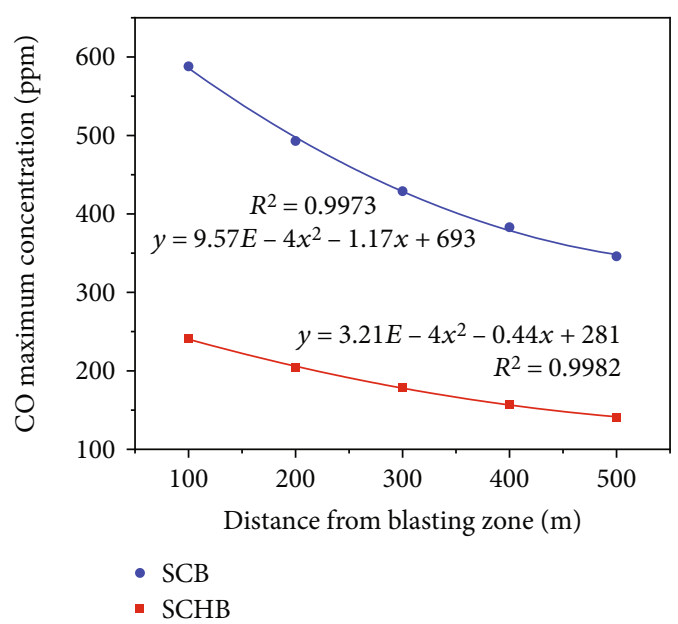

FIgURE 19: Changes in maximum $\mathrm{CO}$ concentration with monitoring distance in four-hole SCB and SCHB.

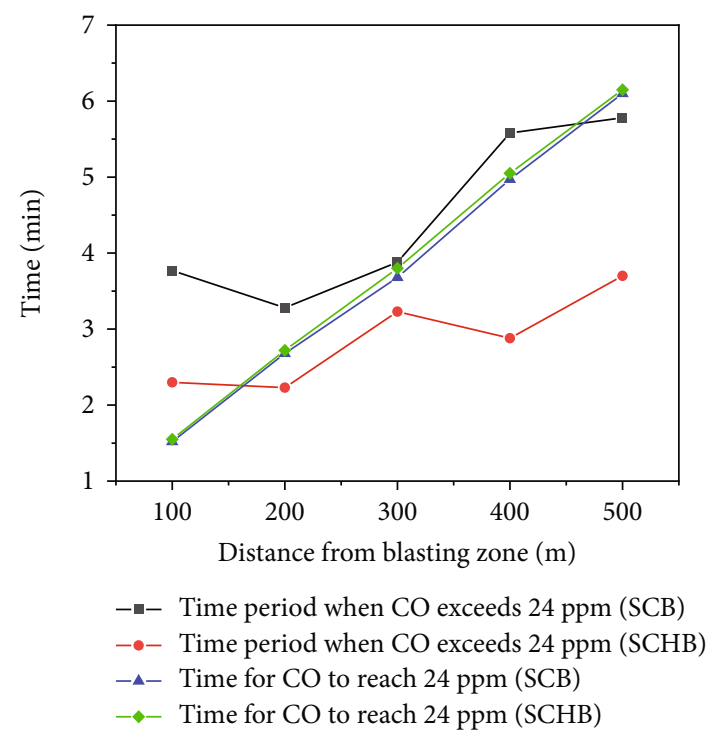

FIgUre 20: Time taken by CO to reach $24 \mathrm{ppm}$ and exceed the same with monitoring distance in four-hole SCB and SCHB.

was shorter than that of SCB. In addition, $\mathrm{CO}$ of SCHB reached the over-limit concentration slightly slower than that of SCB. This was because SCHB produced less CO. When the air volume and wind speed were constant, the time required for the $\mathrm{CO}$ gas mass to move from the blast source to each monitoring point was proportional to the distance. Therefore, the moment at which the over-limit concentration was reached was approximately linear with the monitoring distance.

4.5.3. Four-Hole Blasting. The charge of four-hole blasting was four times that of single-hole blasting and twice that of double-hole blasting. Therefore, the CO concentration from the four-hole blasting was also much greater than that of the single- and double-hole blasting methods (Figure 18). When the air volume was constant, the higher the amount 


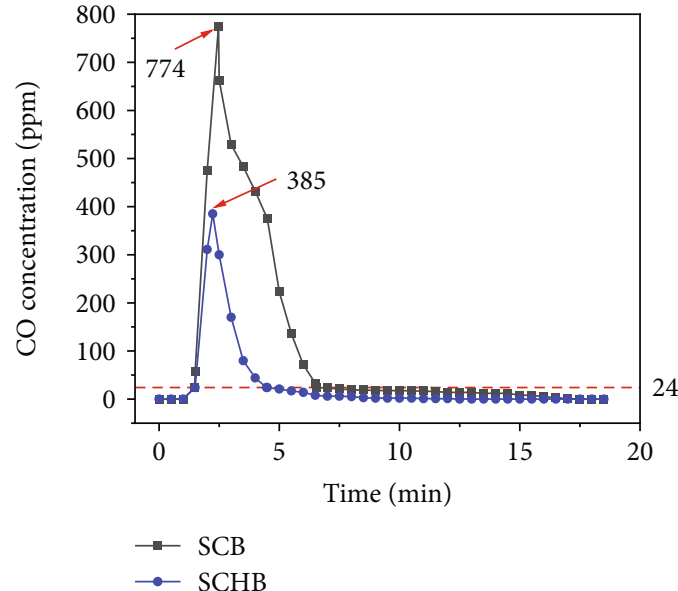

(a)

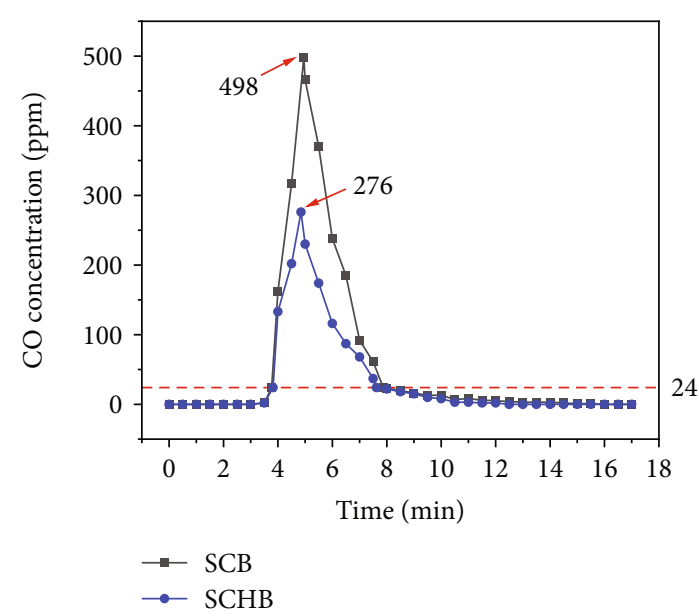

(c)

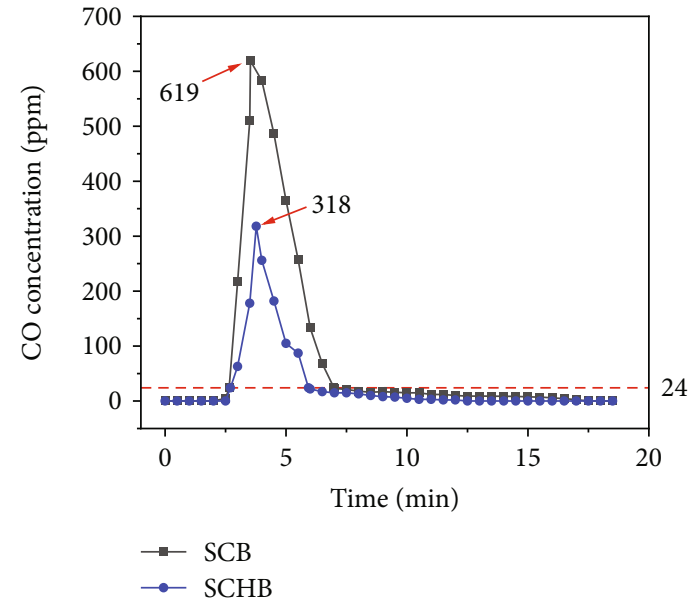

(b)

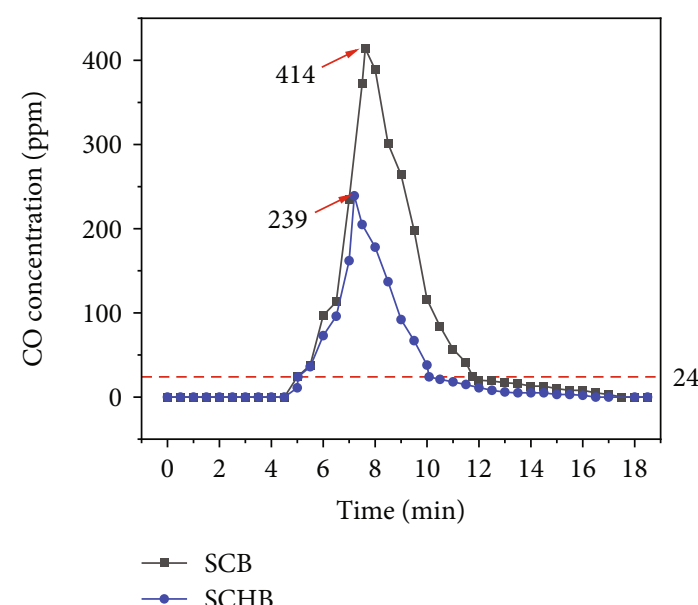

(d)

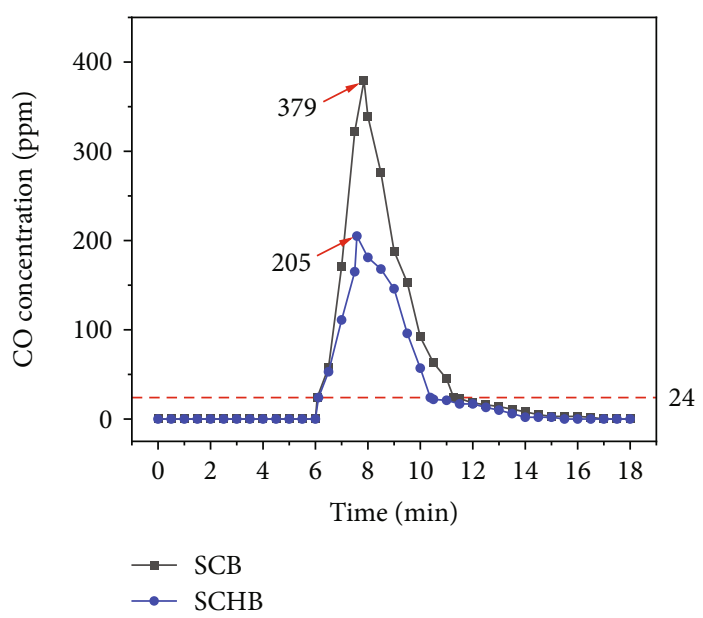

(e)

Figure 21: Time-varying curve of $\mathrm{CO}$ concentration in six-hole blasting at different measuring points: (a) $100 \mathrm{~m}$ from blasting zone, (b) $200 \mathrm{~m}$ from blasting zone, (c) $300 \mathrm{~m}$ from blasting zone, (d) $400 \mathrm{~m}$ from blasting zone, and (f) $500 \mathrm{~m}$ from blasting zone.

of explosives detonated simultaneously, the longer the ventilation time required to dilute the $\mathrm{CO}$ in the gun smoke. During blasting, the atomization of water caused the water and $\mathrm{CO}$ to come in full contact. Under the high temperature and high pressure generated by the blasting, water and $\mathrm{CO}$ generated $\mathrm{CO}_{2}$ and $\mathrm{H}_{2}$, thereby greatly absorbing $\mathrm{CO}$, that is,

$$
\mathrm{CO}+\mathrm{H}_{2} \mathrm{O}=\mathrm{CO}_{2}+\mathrm{H}_{2} \text { (high temperature). }
$$




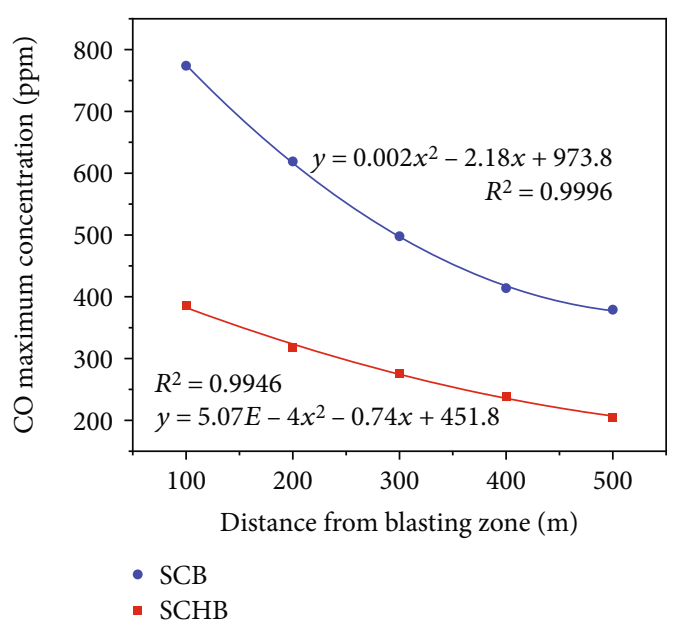

FIGURE 22: Changes in maximum $\mathrm{CO}$ concentration with monitoring distance in six-hole SCB and SCHB.

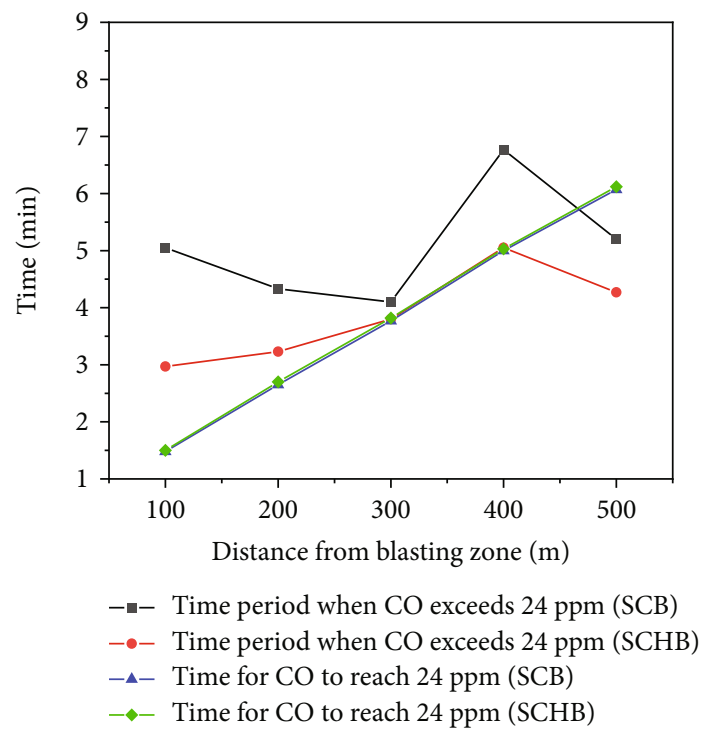

FIgURE 23: Time taken by CO to reach $24 \mathrm{ppm}$ and exceed the same with the monitoring distance in six-hole SCB and SCHB.

The relationship between the maximum CO concentrations of SCB and SCHB with the monitoring distance (Figure 19) is

$$
\begin{aligned}
& y=9.57 E-4 x^{2}-1.17 x+693 \\
& y=3.21 E-4 x^{2}-0.44 x+281
\end{aligned}
$$

The coefficients of determination of these two curves were 0.9973 and 0.9982 , which are close to 1 . This shows that the relationship between the maximum CO concentration and the monitoring distance is a parabola, and the goodness of fit is high. The $\mathrm{CO}$ inhibition rates at the five monitoring points were $59 \%, 59 \%, 58 \%, 59 \%$, and 59\%, respectively. The water medium significantly inhibited $\mathrm{CO}$ and reduced its movement in the lane. The time for $\mathrm{CO}$ to reach the over-limit concentration was almost the same in the two blasting methods (Figure 20). At the five monitoring points, SCB's overrun durations were $3.77,3.28,3.88,5.58$, and 5.78, while those of SCHB were 2.3, 2.23, 3.23, 2.88, and 3.7, respectively. Both blasting methods had the same amount of ventilation, but SCB produced more CO. Hence, SCB's CO overrun time was longer than SCHB.

4.5.4. Six-Hole Blasting. The CO concentration law of six-hole blasting was basically the same as those of the single-hole, double-hole, and four-hole blasting methods (Figures 21-23). However, it was just that the amount of $\mathrm{CO}$ produced by SCB and SCHB increased as the charge increased. The amount of $\mathrm{CO}$ produced by blasting was proportional to the quantity of explosives. Therefore, when the amount of ventilation was constant, the quantity of explosives should be strictly controlled. This can effectively reduce the amount of toxic gas $\mathrm{CO}$, thereby shortening the time of $\mathrm{CO}$ migration and diffusion. The $\mathrm{CO}$ suppression rates at the five monitoring points were $50 \%, 49 \%, 45 \%, 42 \%$, and $46 \%$, respectively. The short-term overrun of $\mathrm{CO}$ was inevitable, but the water mist formed by SCHB at the time of explosion reacted with $\mathrm{CO}$ to generate $\mathrm{CO}_{2}$ and $\mathrm{H}_{2}$, which could effectively decrease the $\mathrm{CO}$ concentration.

\section{Conclusion}

$\mathrm{SCHB}$, as a novel directional roof-cutting technology, uses water as the blasting medium instead of air. It is an environmental, safe, and economical method of directional roof cutting. Conclusions are as follows:

(1) Compared with SCB, SCHB reduces the quantity of explosives required, increases the crack rate of the rock, and saves costs. Therefore, it is a more economical blasting technology

(2) SCHB can decrease the concentration of toxic gases $\mathrm{CO}$, which is beneficial to the health of workers. Thus, it is a green blasting method

(3) Water can absorb the heat generated by blasting. SCHB can reduce the possibility of gas explosion. Hence, it is a safe method

\section{Data Availability}

The data used to support the study can be obtained from the authors.

\section{Conflicts of Interest}

The authors declare that there is no conflict of interest regarding the publication of this paper.

\section{Acknowledgments}

This work was financially supported by the National Key Research and Development Program of China (No. 2016YFC0600901) and the National Natural Science Foundation of China (No. 41941018 and No. 52074300) that are gratefully acknowledged. 


\section{References}

[1] M. C. He, G. L. Zhu, and Z. B. Guo, "Longwall mining "cutting cantilever beam theory" and 110 mining method in China-the third mining science innovation," Journal of Rock Mechanics and Geotechnical Engineering, vol. 7, no. 5, pp. 483-492, 2015.

[2] J. Shang, S. R. Hencher, L. J. West, and K. Handley, "Forensic excavation of rock masses: a technique to investigate discontinuity persistence," Rock Mechanics and Rock Engineering, vol. 50, no. 11, pp. 2911-2928, 2017.

[3] S. B. Tang, R. Q. Huang, S. Y. Wang, C. Y. Bao, and C. A. Tang, "Study of the fracture process in heterogeneous materials around boreholes filled with expansion cement," International Journal of Solids and Structures, vol. 112, pp. 1-15, 2017.

[4] S. Arshadnejad, "Design of hole pattern in static rock fracture process due to expansion pressure," International Journal of Rock Mechanics and Mining Sciences, vol. 123, article 104100, p. 5, 2019.

[5] R. De Silva, P. G. Ranjith, and M. S. A. Perera, "An alternative to conventional rock fragmentation methods using SCDA: a review," Energies, vol. 9, no. 11, article 958, 2016.

[6] Y. M. Lekontsev and P. V. Sazhin, "Application of the directional hydraulic fracturing at Berezovskaya mine," Journal of Mining Science, vol. 44, no. 3, pp. 253-258, 2008.

[7] H. He, L. M. Dou, J. Fan, T. du, and X. Sun, "Deep-hole directional fracturing of thick hard roof for rockburst prevention," Tunnelling and Underground Space Technology, vol. 32, pp. 34-43, 2012.

[8] B. Huang, J. Liu, and Q. Zhang, "The reasonable breaking location of overhanging hard roof for directional hydraulic fracturing to control strong strata behaviors of gob-side entry," International Journal of Rock Mechanics and Mining Sciences, vol. 103, pp. 1-11, 2018.

[9] B. W. Xia, C. W. Liu, Y. Y. Lu, Y. Liu, Z. L. Ge, and J. R. Tang, "Experimental study of propagation of directional fracture with slotting hydraulic blasting," Journal of China Coal Society, vol. 41, no. 2, pp. 432-438, 2016.

[10] C. Liu, B. Xia, Y. Lu, and Y. Gao, "Experimental study on quasi-static pressure of slot hydraulic blasting," Shock and Vibration, vol. 2018, Article ID 6584634, 8 pages, 2018.

[11] Z. Ma, J. Wang, M. He, Y. Gao, J. Hu, and Q. Wang, "Key technologies and application test of an innovative noncoal pillar mining approach: a case study," Energies, vol. 11, no. 10, p. 2853, 2018.

[12] Q. Zhang, M. C. He, J. Wang et al., "Instantaneous expansion with a single fracture: a new directional rock- breaking technology for roof cutting," International Journal of Rock Mechanics and Mining Sciences, vol. 132, article 104399, 2020.

[13] Z. G. Tao, Z. G. Song, M. C. He, Z. G. Meng, and S. H. Pang, "Principles of the roof cut short-arm beam mining method (110 method) and its mining-induced stress distribution," International Journal of Mining Science and Technology, vol. 28, no. 3, pp. 391-396, 2018.

[14] S. Torno, J. Torano, M. Ulecia, and C. Allende, "Conventional and numerical models of blasting gas behaviour in auxiliary ventilation of mining headings," Tunnelling and Underground Space Technology, vol. 34, pp. 73-81, 2013.

[15] S. Torno and J. Torano, "On the prediction of toxic fumes from underground blasting operations and dilution ventilation. Conventional and numerical models," Tunnelling and Underground Space Technology, vol. 96, article 103194, 2020.
[16] Z. Sa, F. Li, B. Qin, and X. Pan, "Numerical simulation study of dust concentration distribution regularity in cavern stope," Safety Science, vol. 50, no. 4, pp. 857-860, 2012.

[17] G. Feng, Q. Liao, and S. Hu, "Numerical simulation of particulate matter 2.5 distribution in a roadway," Scientific Reports, vol. 8, no. 1, article 13220, 2018.

[18] D. Bahrami, L. Yuan, J. H. Rowland, L. Zhou, and R. Thomas, "Evaluation of post-blast re-entry times based on gas monitoring of return air," Mining Metallurgy \& Exploration, vol. 36, no. 3, pp. 513-521, 2019.

[19] J. Abdollahisharif, E. Bakhtavar, and H. Nourizadeh, "Green biocompatible approach to reduce the toxic gases and dust caused by the blasting in surface mining," Environmental Earth Sciences, vol. 75, no. 3, p. 191, 2016.

[20] M. L. Harris and R. J. Mainiero, "Monitoring and removal of CO in blasting operations," Safety Sciences, vol. 45, no. 10, pp. 1393-1405, 2008.

[21] W. Yuan, W. Wang, X. Su, L. Wen, and J. Chang, "Experimental and numerical study on the effect of water-decoupling charge structure on the attenuation of blasting stress," International Journal of Rock Mechanics and Mining Sciences, vol. 124, article 104133, 2019.

[22] Z. Wang, Y. Li, and R. F. Shen, "Numerical simulation of tensile damage and blast crater in brittle rock due to underground explosion," International Journal of Rock Mechanics and Mining Sciences, vol. 44, no. 5, pp. 730-738, 2007.

[23] Q. Ye, Z. Jia, and C. Zheng, "Study on hydraulic-controlled blasting technology for pressure relief and permeability improvement in a deep hole," Journal of Petroleum Science and Engineering, vol. 159, pp. 433-442, 2017.

[24] Z. Cui, "Effect of water-silt composite blasting on the stability of rocks surrounding a tunnel," Bulletin of Engineering Geology and the Environment, vol. 70, no. 4, pp. 657-664, 2011.

[25] Z. Cui, L. Yuan, and C. Yan, "Water-silt composite blasting for tunneling," International Journal of Rock Mechanics and Mining Sciences, vol. 47, no. 6, pp. 1034-1037, 2010.

[26] W. Gu, Z. Wang, J. Chen, J. Liu, and M. Lu, "Experimental and theoretical study on influence of different charging structures on blasting vibration energy," Shock and Vibration, vol. 2015, Article ID 248739, 11 pages, 2015.

[27] J. X. Yang, C. Y. Liu, and B. Yu, “Application of confined blasting in water-filled deep holes to control strong rock pressure in hard rock mines," Energies, vol. 10, no. 11, p. 1874, 2017.

[28] L. Changyou, Y. Jingxuan, and Y. Bin, "Rock-breaking mechanism and experimental analysis of confined blasting of borehole surrounding rock," International Journal of Mining Science and Technology, vol. 27, no. 5, pp. 795-801, 2017.

[29] J. X. Yang and C. Y. Liu, "Experimental study and engineering practice of pressured water coupling blasting," Shock and Vibration, vol. 2017, Article ID 5484598, 12 pages, 2017.

[30] C. Zhu, M. C. He, M. Karakus, X. B. Cui, and Z. G. Tao, "Investigating toppling failure mechanism of anti-dip layered slope due to excavation by physical modelling," Rock Mechanics and Rock Engineering, vol. 53, no. 11, pp. 5029-5050, 2020.

[31] R. Jiang, F. Dai, Y. Liu, and A. Li, "Fast marching method for microseismic source location in cavern-containing rockmass: performance analysis and engineering application," Engineering, 2021.

[32] Q. Meng, H. Wang, M. Cai, W. Xu, X. Zhuang, and T. Rabczuk, "Three-dimensional mesoscale computational 
modeling of soil-rock mixtures with concave particles," Engineering Geology, vol. 277, article 105802, 2020.

[33] S. M. Liu, X. L. Li, D. K. Wang, and D. Zhang, "Experimental study on temperature response of different ranks of coal to liquid nitrogen soaking," Natural Resources Research, 2020.

[34] Z. G. Tao, C. Zhu, X. H. Zheng et al., "Failure mechanisms of soft rock roadways in steeply inclined layered rock formations," Geomatics, Natural Hazards and Risk, vol. 9, no. 1, pp. 1186-1206, 2018.

[35] C. Zhu, X. D. Xu, X. T. Wang et al., "Experimental investigation on nonlinear flow anisotropy behavior in fracture media," Geofluids, vol. 2019, Article ID 5874849, 9 pages, 2019.

[36] Q. Wang, Q. Qin, B. Jiang et al., "Mechanized construction of fabricated arches for large-diameter tunnels," Automation in Construction, vol. 124, article 103583, 2021.

[37] X. L. Li, Z. Y. Cao, and Y. L. Xu, "Characteristics and trends of coal mine safety development," Energy Sources, Part A: Recovery, Utilization, and Environmental Effects, 2020.

[38] Q. X. Meng, W. Y. Xu, H. L. Wang, X. Y. Zhuang, W. C. Xie, and T. Rabczuk, "DigiSim - an open source software package for heterogeneous material modeling based on digital image processing," Advances in Engineering Software, vol. 148, article 102836, 2020.

[39] X. Y. Shang and H. Tkalčić, "Point-source inversion of small and moderate earthquakes from $\mathrm{P}$-wave polarities and $\mathrm{P} / \mathrm{S}$ amplitude ratios within a hierarchical bayesian framework: implications for the geysers earthquakes," Journal of Geophysical Research: Solid Earth, vol. 125, no. 2, 2020.

[40] Q. Zhang, B. X. Huang, M. C. He, and S. Guo, "A numerical investigation on the hydraulic fracturing effect of water inrush during tunnel excavation," Geofluids, vol. 2020, 15 pages, 2020.

[41] Q. Wang, H. Gao, B. Jiang, S. Li, M. He, and Q. Qin, "In-situ test and bolt-grouting design evaluation method of underground engineering based on digital drilling," International Journal of Rock Mechanics and Mining Sciences, vol. 138, article 104575, 2021.

[42] J. L. Pan, "The discussion of rock mechanism by blasting," Blasting, vol. 11, no. 4, pp. 1-6, 1994.

[43] S. H. Chen and C. M. Lin, "Features of rock fragmented by water blasting," Journal of the China Coal Society, vol. 21, no. 1, pp. 24-29, 1996.

[44] Q. Zong, "Investigations into mechanism of fracture formation for grooved hole-well blasting," Chinese Journal of Geotechnical Engineering, vol. 20, no. 1, pp. 30-33, 1998.

[45] Y. Liu, Y. Y. Lu, X. H. Li, and B. W. Xia, "Application of technique of drilling between roof and floor with high pressure pulse water jet," Journal of the China Coal Society, vol. 35, no. 7, pp. 1115-1119, 2010.

[46] J. H. Gao, L. Lu, and Y. Y. He, Shallow Water Explosion and its Destructive Effect, National Defense Industry Press, 2010.

[47] S. Q. Miao, Y. Li, and C. Wang, "Experimental study on hole presplitting blasting with water pressure," Engineering Blasting, vol. 4, no. 4, pp. 19-23, 1998.

[48] Y. S. Liu, H. X. Fu, M. S. Wang, F. B. Chen, and X. B. Zhang, "Experimental research and analysis of mechanics on watercoupling directional fractural charge," Journal of Beijing Jiaotong University, vol. 33, no. 1, pp. 109-112, 2009. 